\title{
Comparison of Two Chemically-Induced Colitis-Models in Adult Zebrafish, Using Optical Projection Tomography and Novel Transcriptional Markers
}

\author{
Simon Haarder1,2, Per W. Kania ${ }^{2}$, Thomas Lindebo Holm³ ${ }^{3}$ Maki Ohtani2 ${ }^{2}$ Kurt Buchmann² \\ ${ }^{1}$ Novo Nordisk-LIFE In Vivo Pharmacology Centre, Frederiksberg, Denmark \\ ${ }^{2}$ Laboratory of Aquatic Pathobiology, Department of Veterinary Disease Biology, Faculty of Health and Medical Sciences, University of \\ Copenhagen, Frederiksberg, Denmark \\ ${ }^{3}$ Global Research, Novo Nordisk A/S, Måløv, Denmark \\ Email: haarder@sund.ku.dk
}

How to cite this paper: Haarder, S., Kania, P.W., Holm, T.L., Ohtani, M. and Buchmann, K. (2016) Comparison of Two ChemicallyInduced Colitis-Models in Adult Zebrafish, Using Optical Projection Tomography and Novel Transcriptional Markers. Open Journal of Immunology, 6, 154-180.

http://dx.doi.org/10.4236/oji.2016.64016

Received: August 29, 2016

Accepted: December 25, 2016

Published: December 28, 2016

Copyright $\odot 2016$ by authors and Scientific Research Publishing Inc. This work is licensed under the Creative Commons Attribution International License (CC BY 4.0).

http://creativecommons.org/licenses/by/4.0/

\section{(c) (i) Open Access}

\begin{abstract}
Crohn's disease and ulcerative colitis-inflammatory bowel diseases (IBD)-are chronic conditions with an inadequately understood pathogenesis. Employing a set of novel molecular markers in a gene expression assay (qPCR), we have used adult zebrafish to investigate two acute inflammatory models, induced by the haptenizing agents oxazolone and TNBS. In addition, goblet cell dynamics in the scales and intestine and 5-HT (serotonin) in intestinal tissues were investigated through optical projection tomography. Gene expression studies revealed a distinct and significant upregulation of proinflammatory cytokines, acute-phase reactants and metalloprotease 9 in both chemical models, primarily after 72 hours. In comparison, transcription factors and cytokines associated with Th1 and Th17 (Crohn's) and Th2 (ulcerative colitis) were mainly not affected in this acute setting. However, elevated transcript levels were detected in Foxp3, IL-10 and T-bet, which are linked with tolerance and Tregs in mammals. Goblet cells in scales were depleted in both chemical models and in the intestine of oxazolone-treated fish. A marked 5-HT signal was noted in intestinal tissue of some chemically treated zebrafish. In conclusion, a distinct acute inflammatory reaction was induced in both chemical models. Further, oxazolone and TNBS did not result in clear-cut Th2 and Th1/Th17 pathway signaling at this early timepoint, but the applied molecular tools may provide further insight to the IBD pathogenesis and translational value of the IBD zebrafish model.
\end{abstract}




\section{Keywords}

IBD, Zebrafish, qPCR, Disease Model, OPT

\section{Introduction}

Inflammatory bowel disease (IBD) is a chronic and debilitating disorder associated with considerable morbidity and reduced quality of life. Factors important for the disease include genetic susceptibility, the host immune system and various environmental factors, most notably the gut microbiota, but the condition exhibits great variety in development and severity [1]. IBD is subdivided into two major clinical forms, Crohn's disease (CD) and ulcerative colitis (UC), which differ in several aspects, e.g. affected tissue in gastrointestinal tract, depth of mucosal inflammation and other micropathological features. Further, in $\mathrm{CD}$ the predominant cytokines driving the disease are governed by T-helper cell (Th) 1 and Th17 pathways, whereas ulcerative colitis is dominated by a Th-2-like cytokine response [2]. However, these inflammatory conditions exhibit a complex etiology and much basal pathogenesis still remains to be elucidated. For instance, symptoms and pathology which cannot be assigned to CD or UC is referred to as indeterminate colitis, a condition encountered most frequently in children and in approximately $10 \%$ of patients with colitis [3] [4]. The zebrafish (Danio rerio) is an emerging animal model in the field of human disease studies due to its many advantageous traits [5]. The majority of immune molecules relevant to IBD pathogenesis are also found in zebrafish and several colitis-studies have been performed using adult and larval zebrafish [6]-[12]. From these studies it is known that an inflammatory state relevant to the human condition can be engineered in zebrafish, but the role of underlying activators-e.g. transcription factors-has been inadequately studied in this model organism. Using adult zebrafish, we are studying the basal disease development of IBD and for the purpose we have developed a series of novel markers which can be used for two hapten-mediated IBD-like models (using oxazolone and TNBS), with conditions mimicking UC and CD, respectively. Similar approaches were previously applied for mammalian models [13] but the present work on the two zebrafish models applies a novel set of Taqman probe based qPCR assays, investigating a wide array of essential immune genes, e.g. cytokines, transcription factors, acute-phase proteins, Toll-like receptors. Additionally, we have visualized the presence of serotonin in intestinal cells in zebrafish using optical projection tomography, a bioimaging method based on the use of specific antibodies that only recently have been implemented in fish immunology studies [14] [15]. Serotonin (5-HT) is a ubiquitous and highly conserved neurotransmitter that plays a pivotal role in a variety of behaviors (e.g. fear, aggressiveness), physiological functions (pain, vascular function etc.), and 5-HT signaling was reported to decrease in mucosal biopsies from human patients with UC whereas colitis-models in rodents have reported an increase [16]. In zebrafish, 5-HT signalling has been detected in a number of tissues, for example the brain and CNS as well as in the intestine [17] 
[18]. The 5-HT involvement in neutrophil invasion and extracellular traps (NETS) in inflammatory tissues [19] suggest that 5-HT signalling may be worth investigating in the zebrafish-colitis model. Finally, it has been reported recently that the skin of fish displays many of the features found in mammalian mucosa associated lymphoid tissue, including the gut [20]. Goblet cells are an important intestinal cell type that is routinely evaluated in IBD-assessment. In human patients, depletion is seen in UC whereas a differentiation of cells often, but not always, is observed in CD, features which can be reproduced in both rodent and zebrafish models [13] [21] [22]. We have evaluated the goblet cell population in the scales and intestine of our two colitis models in order to assess whether a systemic factor is affecting goblet cell function. If so, this procedure could be employed in future models as it is much less invasive compared to intestinal studies. Overall, the objective of the current study was to investigate the underlying disease mechanisms of IBD using a multifactorial approach including multiple technologies, several of which have not been employed earlier in zebrafish models. This improved zebrafish model with associated methodologies may contribute to improved understanding of IBD pathogenesis.

\section{Materials and Methods}

\subsection{Ethics Statement}

All experiments were approved by the Experimental Animal Inspectorate under the Ministry of Food, Agriculture and Fisheries (license: 2013-15-2934-00867).

\subsection{Housing Conditions}

Adult wild-type zebrafish (Danio rerio) ( $0.5 \mathrm{~g}-0.8 \mathrm{~g}$ ) were kept at the experimental fish facilities at University of Copenhagen, Frederiksberg. They were acclimatized in a $160 \mathrm{~L}$ aquarium with freshwater ( $\mathrm{pH} 7.4$, conductance $550 \mu \mathrm{S})$ equipped with Eheimbiofilters (Eldorado, Denmark) and aerated by oxygen stones for one week prior to experimentation. Fish were provided with commercial feed (ZM Ltd, UK) twice daily and maintained at a $14 \mathrm{~h}$ light and $10 \mathrm{~h}$ dark cycle in a thermostat controlled room $\left(28.5^{\circ} \mathrm{C} \pm\right.$ $0.5^{\circ} \mathrm{C}$ ). Samples from randomly chosen fish did not reveal macroscopically or microscopically visible pathogens when examined, according to standard parasitological examination protocols [23]. Further, no bleedings or organ abnormalities were observed.

\subsection{Induction of Oxazolone- and TNBS-Colitis}

Twenty-four hours before the experimental procedure, groups of sixfish were placed in1 Ltanksand feeding was stopped. For induction of colitis, 12 fish $(2 \times 6)$ were anaesthetized with $100 \mathrm{mg} / \mathrm{L}$ MS-222 (Tricainemethanesulfonate; cat. No. A5040, Sigma-Aldrich, Denmark) whereupon either 0.6\% oxazolone (4-ethoxymethylene-2-phenyl 2 oxazolin-5-one; cat. No. E0753, Sigma-Aldrich, Denmark) or $160 \mu \mathrm{m}$ TNBS (Picrylsulfonic acid solution; cat. No. 92822, Sigma-Aldrich, Denmark), dissolved in 50\% and $30 \%$ ethanol, respectively, was rectally instilled with a $20 \mu \mathrm{l}$ Hamilton syringe equipped with a blunt-endneedle (cat. No. HAMI7768-01, VWR, Denmark) (total volume $=1.0$ 
$\mu \mathrm{l}$ per $100 \mathrm{mg}$ body weight). All experiments were conducted in duplicate. For oxazolone, this dosage was chosen based on pilot experiments which showed that $0.6 \%$ and $1.0 \%$ but not $0.2 \%$ oxazolone resulted in distinct goblet cell depletion when compared to control fish (Supplementary Material Figure S1). The concentration of TNBS used in the experiment was considered optimal based on the literature [10]. Control groups received 50\% ethanol (oxazolone solvent), 30\% ethanol (TNBS solvent) or tap water. Treated fish were returned to their tanks and observed every second hour. The water in each tank was partly exchanged (50\%) on a daily basis until euthanization. Fish which were displaying continuously erratic behavior, exhibited distinct bleedings and/or suffering from severe hyperventilation were considered moribund and euthanized as described below. These fish were not included in the subsequent analysis.

\subsection{Sampling}

Surviving fish from each group was euthanized with an overdose of MS-222 (200 mg/L) at6hpi and $72 \mathrm{hpi}$, the spinal cord was severed, and the intestine was isolated aseptically. For qPCR analysis, the intestine ( $\mathrm{n}=6-8$, per group per time point)was immediately placed in RNAlater (cat. no R0901, Sigma-Aldrich, Denmark) for $24 \mathrm{~h}$ at $4^{\circ} \mathrm{C}$, then stored at $-20^{\circ} \mathrm{C}$. For goblet cell studies, the zebrafish carcass and intestine $(\mathrm{n}=8$ 10 and $\mathrm{n}=2$, respectively, per group per time point) was transferred to $10 \%$ neutral buffered formalin (formaldehyde solution 4\% "Lillie", cat. No. 10.005.000, HounisenLaboratorieudstyr A/S, Denmark) for 24 hours at room temperature, and then stored in $70 \% \mathrm{EtOH}$ until further use (see below).

\subsection{Design and Optimization of a Panel of TaqMan Probe Based qPCR Assays}

No probe base $\mathrm{qPCR}$ assays for immune and IBD relevant genes were described when the literature was scrutinized. Therefore 38 TaqMan probe $\mathrm{qPCR}$ assays including 3 reference genes were evolved. Primers and probes were designed with the aid of the internet based source Primer3Plus [24]. Sequences of primers and probes, GenBank accession numbers, and product length can be found in Supplementary Table S1.

Forward and reverse primer combinations for the individual assays were assessed by using Brilliant II SYBR Green QPCR Master Mix (cat. No. 600828; AH diagnostics, Denmark) and melting curve analysis. The $\mathrm{qPCR}$ products were also assessed by $2 \%$ ethidium bromide stained agarose gel electrophoresis. Thus only combinations having a single product and no primer dimer formation were selected. Efficiencies of the final assays were all within $100 \% \pm 5 \%$ according to dilution series of templates and analysis of the cumulative fluorescence curves using the software LinRegPCR version 2014.6 [25].

Primers and probes (TAG Copenhagen A/S, Denmark) were designed to have annealing temperatures close to $60^{\circ} \mathrm{C}$ and $67^{\circ} \mathrm{C}$, respectively. Probes were labeled at the 5' end with FAM and with Blackhole Quencher 1 at the 3' end. The Brilliant II QPCR MasterMix (cat. No. 600815; AH diagnostics, Denmark) was used during qPCR with the FAM labeled probes.

In general the annotations in GenBank were used. The protein S100A8, a marker for 
presence of calprotectin associated with neutrophils in IBD [26] [27] has a homologue (GenBank ass. No. BC163954) with high identity in D. rerio. This Genbank entry has the annotation $\mathrm{S100A10B}$, which is a gene encoding a calcium-binding protein involved in plasma membrane transport [28]. However, when blasting the derived protein sequence at NCBI, highest homology was revealed towards S100A1 both in mammals and other fish species. Thus, the term S100A1 is used in this study for GenBank ass. No. BC163954.

\subsection{Quantitative Real-Time PCR (qPCR)}

Tissues were homogenized using the Tissue Lyser II (Qiagen, Denmark), for $2 \times 30 \mathrm{sec}$. at $20 \mathrm{~Hz}$. RNA isolation, RNA product assessment and cDNA synthesis was performed as described by Haarder et al. [29]. Gene expression levels were assessed using quantitative real-time PCR for genes encoding cytokines ((IL-1 $\beta$, IL-4/13, IL-6, IL-8 (Cxcl8), IL-10, IL-12, IL-17, IL-22, IL-23, IFN- $\gamma$, mmp9, TGF- $\beta$, TNF- $\alpha$ )), immunoglobulins (IgM, IgZ), cellular receptors (CD4, CD8), acute-phase proteins (C3, CRP, SAA), toll-like receptors and adaptors (TLR-2, TLR-3, TICAM-1, MyD88), transcription factors (Foxp3, GATA-3, NF- $\kappa$ b, STAT-3, STAT-4, STAT-6, T-bet) and S100 calciumbinding protein A1 (S100A1), a protein involved in neurotransmitter signaling (for primer sequences and additional information, see Table S1 in Supplementary Material ). The involvement of some of the investigated genes in the signaling pathways of the different T-cell subsets is depicted in Figure 1. Three household genes were used as comparative controls: RPL-13, ELF-1 and B-actin. The qPCR assays were carried out in the Stratagene Mx3005 $\mathrm{P}^{\mathrm{Tm}}$ system (AH Diagnostics AS, Denmark) using the same conditions as in Haarder et al. [29].

\subsection{Goblet Cells}

From each carcass, scales were randomly chosen from the lateral side of the fish and removed using fine forceps. The scales were then rinsed in distilled water before staining for acid mucopolysaccharides in 1\% Alcian blue (cat. No. A5268, Sigma-Aldrich, Denmark) in 3\% glacial acetic acid (cat. No. ARK2183, Sigma-aldrich, Denmark) for 1 hour, rinsed again in distilled water, and mounted on microscope slides in Aquatex ${ }^{\oplus}$ (cat. No. 1.08562.0050, VWR, Denmark). Between 1 and 4 scales per fish were investigated. For each scale, all stained goblet cells within the visual field were counted in two different areas of $0.64 \mathrm{~mm}^{2}$, then pooled, at $\times 200$ magnification using an Olympus $\mathrm{CH} 30$ microscope (Olympus, Denmark). Intestines were embedded in paraffin and processed according to standard histological procedures. The obtained five micrometer sections were stained with $1 \%$ Alcian blue in $3 \%$ glacial acetic acid for 30 minutes. The number of goblet cells were counted and analyzed as described above for the scales. However, only two intestines per group per time point were available, so the goblet cell population was assessed in three "pooled" areas per intestine. Due to the low number of intestinal samples ( $\mathrm{n}=2$ per experimental group) no statistics were performed. 


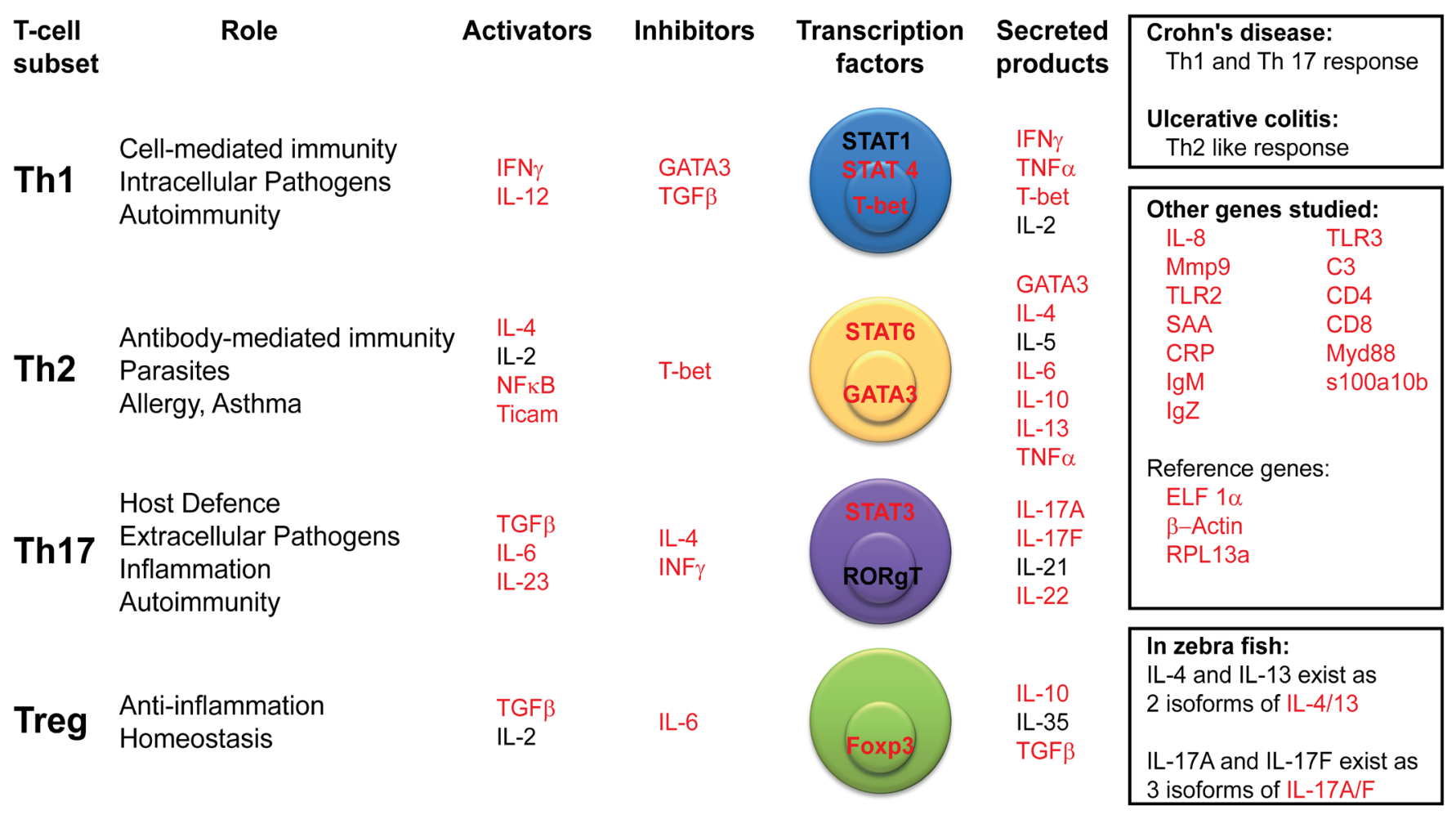

Figure 1. T-cell subset of mammalians and some of the involved genes. Genes in red colour are investigated in zebrafish in the present study.

\subsection{Optical Projection Tomography (OPT)}

In order to visualize 5-HT in intestinal tissue from zebrafish, TNBS or oxazolone was instilled in experimental fish (3 fish per group, no duplicate) as described above; control fish were given $50 \%$ ethanol. The fish were euthanized 72 hpi (overdose of MS-222, $200 \mathrm{mg} / \mathrm{L})$. A series of unchallenged zebrafish $(\mathrm{n}=3)$ were euthanized and the brains were used to optimize procedures, following a slightly modified protocol of Alantentalo et al. [30]. In both cases, tissue samples were fixed in freshly prepared $4 \%$ paraformaldehyde (PFA) for three hours at $4^{\circ} \mathrm{C}$, washed in PBS for 30 minutes, then dehydrated stepwise in methanol (MeOH; 33\% -> 66\% -> 100\%) for 15 minutes/step. Subsequently, in order to quench autofluorescence, samples were incubated in methanol: dimethyl sulfoxide (DMSO): $30 \% \mathrm{H}_{2} \mathrm{O}_{2}$ (2:1:3) overnight at room temperature, then washed for $2 \times 30$ minutes in $100 \%$ methanol before being transferred to $-80^{\circ} \mathrm{C}$ for $1 \mathrm{~h}$ and then kept at room temperature for $1 \mathrm{~h}$. This freeze/thaw cycle was repeated 5 times. Tissues were subsequently rehydrated in increasing concentrations $(33 \%, 66 \%$ and $100 \%$ ) of TBST (50 mM Tris-HCl, $150 \mathrm{mM} \mathrm{NaCl}, 0.1 \%$ Triton X-100, $\mathrm{pH} 7.4$ ) for 15 minutes per step. To minimize nonspecific signals, the samples were kept in blocking solution (TBST with $10 \%$ goat serum and $0.01 \% \mathrm{NaN}_{3}$ ) for $24 \mathrm{~h}$ at room temperature, before being incubated with Protein-G purified anti-serotonin rabbit IgG $(10 \mu \mathrm{g} / \mathrm{ml}$, diluted 5000 fold) (S5545, Sigma-Aldrich, Denmark)in blocking solution for $48 \mathrm{~h}$ at room temperature. The samples were washed in TBST overnight, and then incubated with 1:1000 fold diluted secondary antibodies Alexa Flour ${ }^{\circledast} 594$ conjugated goat anti-rabbit 
IgG (Thermo Fisher Scientific) for $48 \mathrm{~h}$ at room temperature. Following another washing step in TBST, the tissues were mounted in 1\% Ultrapure ${ }^{\text {Tit }}$ Low Melting Point Agarose (Invitrogen, Denmark). The agarose blocks were trimmed, dehydrated in 100\% methanol for $24 \mathrm{~h}$ and cleared in BABB (1:2 benzyl alcohol, benzyl benzoate) for $48 \mathrm{~h}$ in the dark. The now transparent agarose blocks were glued onto a metal disc and photographed using a Bioptonic 3001M OPT scanner (Bioptonic, UK). A series of 800 images was taken of each specimen during a 360 degrees rotation cycle. The Bioptonic $3001 \mathrm{M}$ OPT scanner records both transmission and emission of light. We used the emitted light to detect the auto-fluorescence of tissues or the Alexa Fluor 594 fluorophore. GFP and TXR filters were used to detect auto-fluorescence and the Alexa Fluor 594 fluorophore emission, respectively. Overlaying of the captured images was performed by Adobe Photoshop CS6, and any possible artifacts were removed manually. The captured images were reconstructed with NRecon software (Bruker microCT, Belgium) and then arranged as a 3D image with Bioptonic Viewer software (Bruker microCT); Overlaying of the images was performed using Adobe Photoshop CS6.

\subsection{Statistics}

In general, replicate groups were tested with a two-tailed t-test $(\mathrm{p}<0.05)$ and pooled if they were not significantly different. Student's t-test was used to compare the mean densities of goblet cells in scales from the different experimental groups, and p-values < 0.05 were considered significant. The $\mathrm{qPCR}$ data was analysed using the $2^{-\Delta \Delta \mathrm{Ct}}$ method [31]. Briefly, change in threshold cycle $-\Delta \mathrm{C}_{\mathrm{t}}$-was calculated as the difference between the target gene and the reference gene for individual samples, and $\Delta \Delta \mathrm{C}_{\mathrm{t}}$ as the difference between the $\Delta \mathrm{Ct}$ of the control group and the $\Delta \mathrm{Ct}$ of the experimental groups. Data are presented as the fold change of the ethanol group, oxazolone group and TNBS group compared to control (water-exposed)fish; a two-fold change (or more) in expression with p-values $<0.05$ was considered significant. Furthermore, data was tested for normality using the Kolmogorov-Smirnov test for Gaussian distribution. The cases failing the normality test was subjected to the nonparametric Mann-Whitney test.

\section{Results}

\subsection{Induction of Colitis}

Based on the humane endpoints defined in the Methods section, 2 fish from the TNBS group as well as 4 fish from the oxazolone group (out of 12 fish, in both groups) were euthanized before $6 \mathrm{hpi}$; fish were also euthanized in TNBS $(\mathrm{n}=3)$ and oxazolone groups $(\mathrm{n}=3)$ before $72 \mathrm{hpi}$. No fish from the control groups were showing obvious signs of distress and, accordingly, none were euthanized (Table 1).

\subsection{Goblet Cells}

Mucous cell densities in the epidermal part of zebra fish scales did not differ significantly between the experimental groups at $6 \mathrm{hpi}$, whereas the density decreased significantly in oxazolone and TNBS-treated groups after 72 hpi when compared with con- 
trols (Figure 2). In the intestine, there was no apparent difference in the number of goblet cells in fish from TNBS-exposed group at both time points compared to unchallenged controls. In contrast, a depletion tendency was noted in the oxazolone group at 6 and 72 hpi (Table 2).

\section{3. qPCR}

The expression level of 35 immune genes in zebrafish in response to TNBS and oxazolone was investigated in this study. The gene expression levels for each gene compared to controls are listed in Supplementary Material (Table S2). Significantly regulated genes are depicted in Figures 3-5. The only gene exhibiting significant expression and a

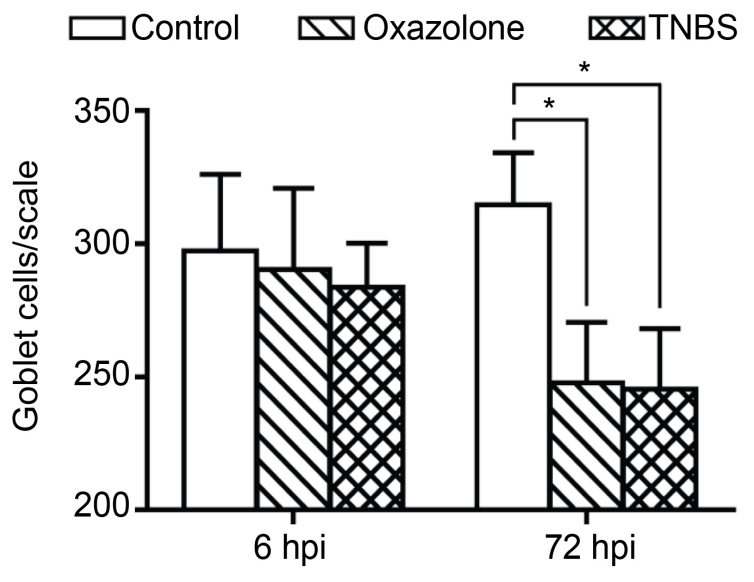

Figure 2. Mucous cell densities in zebrafish scales exposed to $0.6 \%$ oxazolone or $160 \mu \mathrm{m}$ TNBS. Sampling took place at 6 and 72 hpi. 1 to 4 scales were investigated from $8-10$ fish per experimental group per time point. ${ }^{*}$ indicates $p<0.05$.

Table 1. Number of fish euthanized at 6 or 72 hours after treatment depending on experimental group. Each group held 12 fish $(2 \times 6)$ at the start of the experiment.

\begin{tabular}{ccccccccc}
\hline & \multicolumn{2}{c}{ Control } & \multicolumn{2}{c}{ Ethanol } & \multicolumn{2}{c}{ Oxazolone } & \multicolumn{2}{c}{ TNBS } \\
\cline { 2 - 8 } & 6 hpi & 72 hpi & 6 hpi & 72 hpi & 6 hpi & 72 hpi & 6 hpi & 72 hpi \\
\hline No of fish Sampled & 12 & 12 & 12 & 12 & 8 & 9 & 10 & 9 \\
\hline
\end{tabular}

Table 2. Mucous cell densities in zebrafish intestines exposed to $0.6 \%$ oxazolone or $160 \mu \mathrm{m}$ TNBS. Fish ( $\mathrm{n}=2$, per group) was euthanized and sampled after 6 or 72 hours post experimental treatment.

\begin{tabular}{|c|c|c|c|c|c|c|}
\hline & & $6 \mathrm{hpi}$ & & & 72 hpi & \\
\hline Treatment & Control & $0.6 \%$ oxazolone & $\begin{array}{c}160 \mathrm{mM} \\
\mathrm{TNBS}\end{array}$ & Control & $0.6 \%$ oxazolone & $\begin{array}{c}160 \mathrm{mM} \\
\mathrm{TNBS}\end{array}$ \\
\hline $\begin{array}{l}\text { Mucous cell } \\
\text { density per } \\
\mathrm{mm}^{-2}\end{array}$ & 268 & 171 & 262 & 250 & 140 & 257 \\
\hline
\end{tabular}


non-Gaussian distribution was IL- $1 \beta$. However, the non-parametric Mann-Whitney test on the IL- $1 \beta$ data showed significant differences in expression $(\mathrm{p}=0.0256)$.

\subsubsection{Cytokines, Acute-Phase Proteins and S100A1}

IL- $1 \beta$, TNF- $\alpha$ and mmp9 were significantly up-regulated in TNBS and oxazolone after 6 and 72 hpi. The IL-10 gene was significantly up-regulated in the ethanol and TNBS group-2.1 and 3.2 fold, respectively-72 hpi. TGF- $\beta$ and all three genes encoding
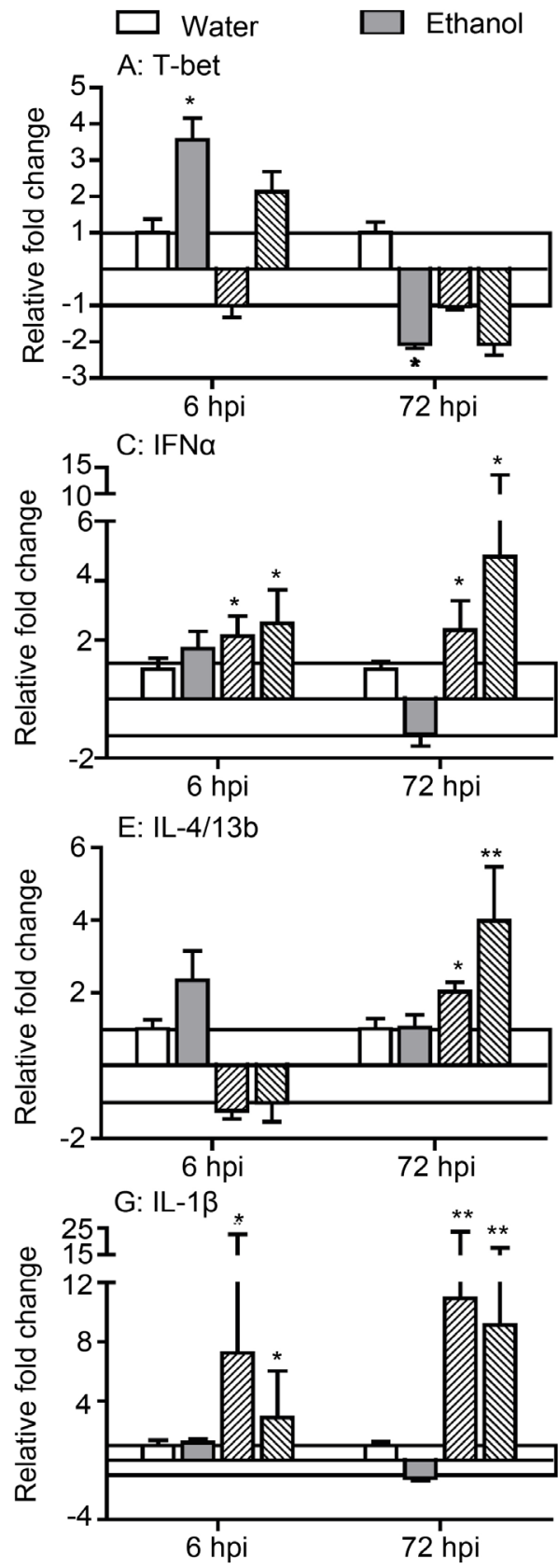
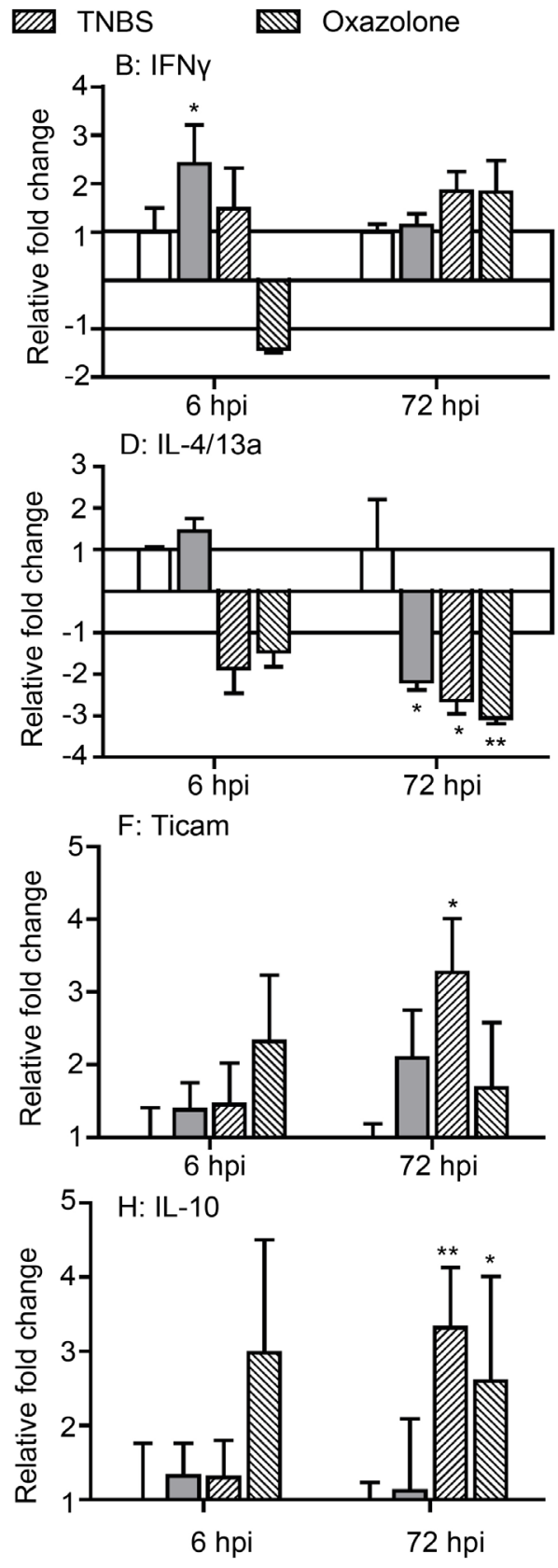

Figure 3. Significant regulation of immune genes following exposure to oxazolone, TNBS or ethanol. Gene expression values are compared against control (water) values. ${ }^{*}$ indicates $\mathrm{p}<0.05$; ${ }^{* *}$ indicates $\mathrm{p}<0.01$. 

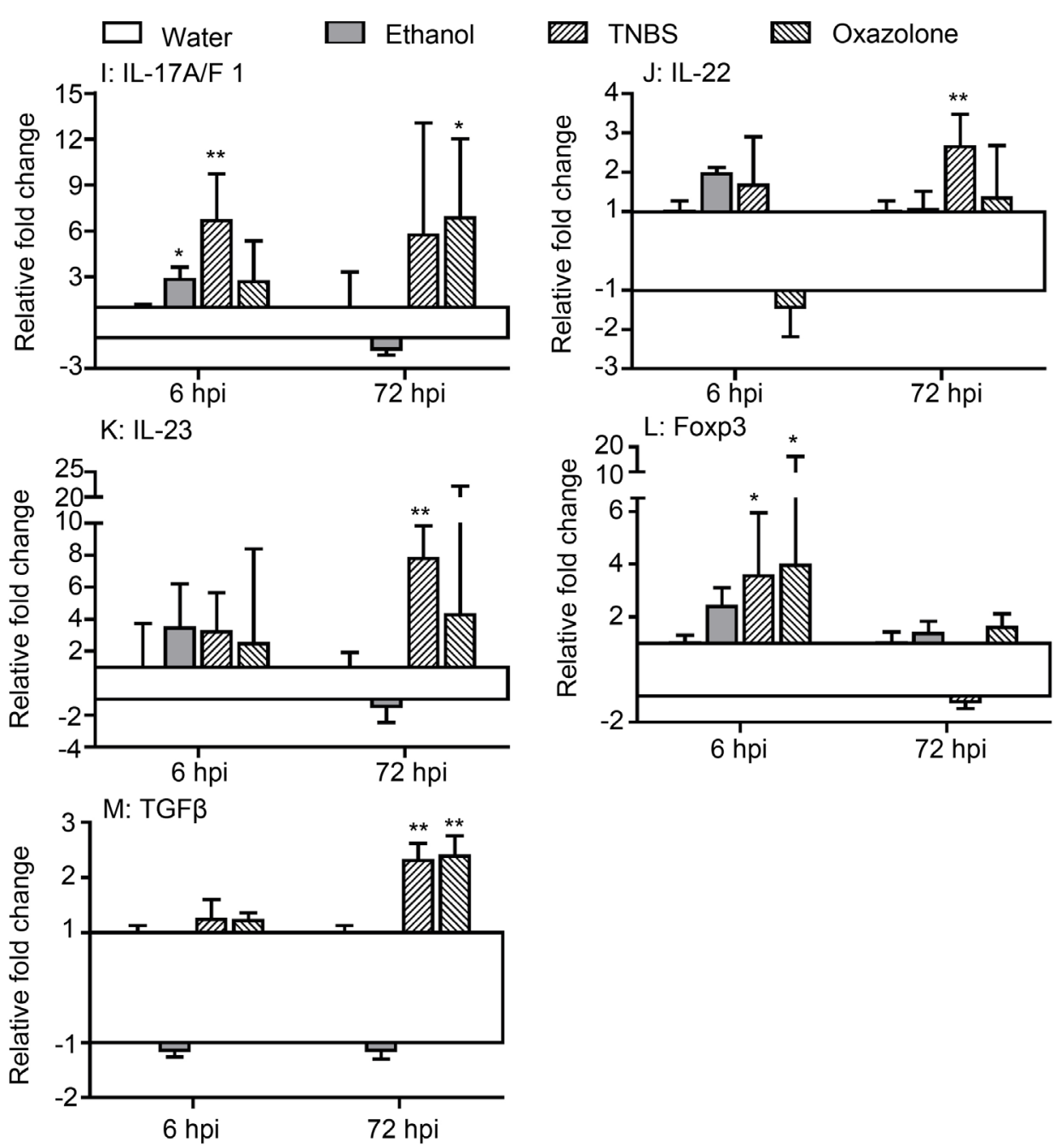

Figure 4. Significant regulation of immune genes following exposure to oxazolone, TNBS or ethanol. Gene expression values are compared against control (water) values. ${ }^{\star}$ indicates $\mathrm{p}<0.05$; ${ }^{*}$ indicates $\mathrm{p}<0.01$.

acute-phase proteins exhibited significantly elevated expression levels in challenged groups after 72 hpi. The gene encoding S100A1 was significantly up-regulated after 6 and $72 \mathrm{hpi}$ in the TNBS group and after 6 and $72 \mathrm{hpi}$ in the ethanol and oxazolone group, respectively. The IL-4/13 and IL-17 genes exist in zebrafish as two and three isoforms, respectively. The expression pattern was not identical in the different isoforms. Thus, the IL-4/13a gene was down-regulated at $72 \mathrm{hpi}$ whereas the IL-4/13b gene was up-regulated at the same time point

The genes encoding IL-6, IL-12 and IL-23 were expressed at low levels and no $C_{T}$ values were obtained from most of the samples. Further, significantly altered gene expression was not observed between challenge and control groups with regards to all three genes. IL-8 was generally expressed at low levels, but a significant up-regulation was seen in TNBS and oxazolone groups (4.8 and 13.8 fold, respectively) after $72 \mathrm{hpi}$. IL-22 was significantly up-regulated in the TNBS group after $72 \mathrm{hpi}$. The gene expression 

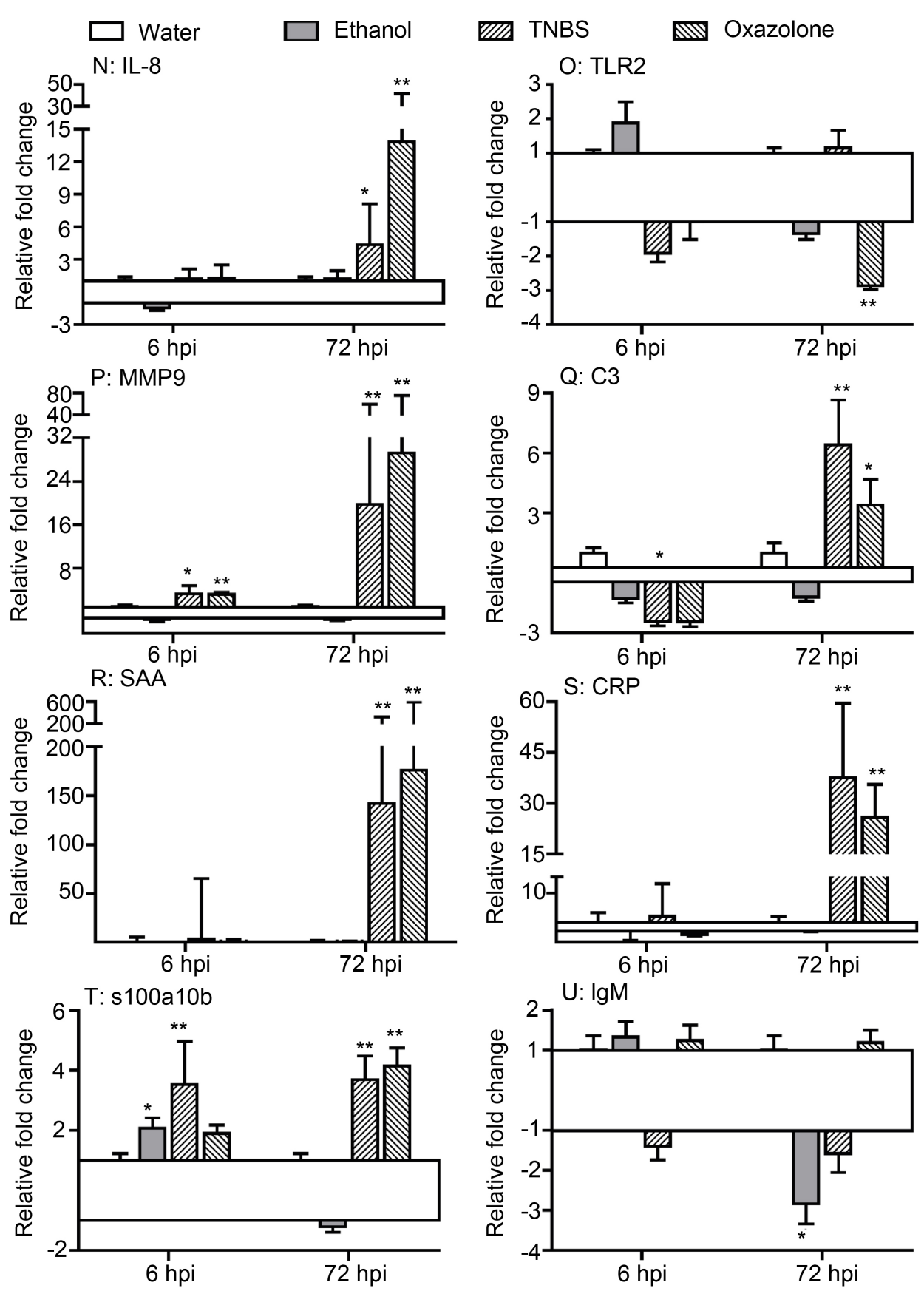

Figure 5. Significant regulation of immune genes following exposure to oxazolone, TNBS or ethanol. Gene expression values are compared against control (water) values. ${ }^{\star}$ indicates $\mathrm{p}<0.05$; **indicates $\mathrm{p}<0.01$.

of IFN- $\gamma$ was only significantly altered in the ethanol group after 6 hpi.

\subsubsection{Immunoglobulins and Cellular Receptors}

A slight, but significant, down-regulation was seen in the gene encoding IgM after 72 hpi in the ethanol group. The IgZ gene was not significantly regulated. CD4 and CD8 gene expression levels were not significantly affected by TNBS and oxazolone treatment 
at any time point.

\subsubsection{Toll-Like Receptors and Adaptors (TLR-2, TLR-3, TICAM-1, MyD88)}

The TLR-2 gene was significantly down-regulated ( 2.9 fold) in the oxazolone group after $72 \mathrm{hpi}$, whereas TICAM-1 gene expression was tripled after $6 \mathrm{hpi}$ in the TNBS group. No change was detected in the remaining genes.

\subsubsection{Transcription Factors (Foxp3, GATA-3, NF- $\kappa b$, STAT-3, STAT-4, STAT-6, T-bet)}

In addition to NF- $\kappa$ b and GATA-3, none of the three STAT-genes, were significantly regulated when compared to controls. The gene encoding Foxp3 was significantly up-regulated after 6 hpi in both TNBS and oxazolone groups (3.4 fold and 4.0 fold, respectively), whereas T-bet gene expression was significantly up-regulated at both time points in the ethanol group.

\subsubsection{Visualization of 5-HT (Serotonin) in Zebrafish Brain and Intestine by OPT}

We detected 5-HT in zebrafish brain and intestine using optical projection tomography (OPT). In the brain, strong signals were found especially in the cerebellum (Figure 6). Distinct 5-HT signals were detected in intestinal tissue of one out of three zebrafishin the groups which had received TNBS and oxazolone when compared to untreated controls (Figure 7). In some control fish, false positive signals were seen with the intestinal content, probably resulting from autofluorescence or the primary antibody reacting with leftover food in the intestine (Figure 8).

\section{Discussion}

The present study has demonstrated a distinct inflammatory reaction, primarily innatedriven, in two acute zebrafish colitis models. No major difference was seen in the immunological response invoked by the two haptenizing agents, oxazolone and TNBS.
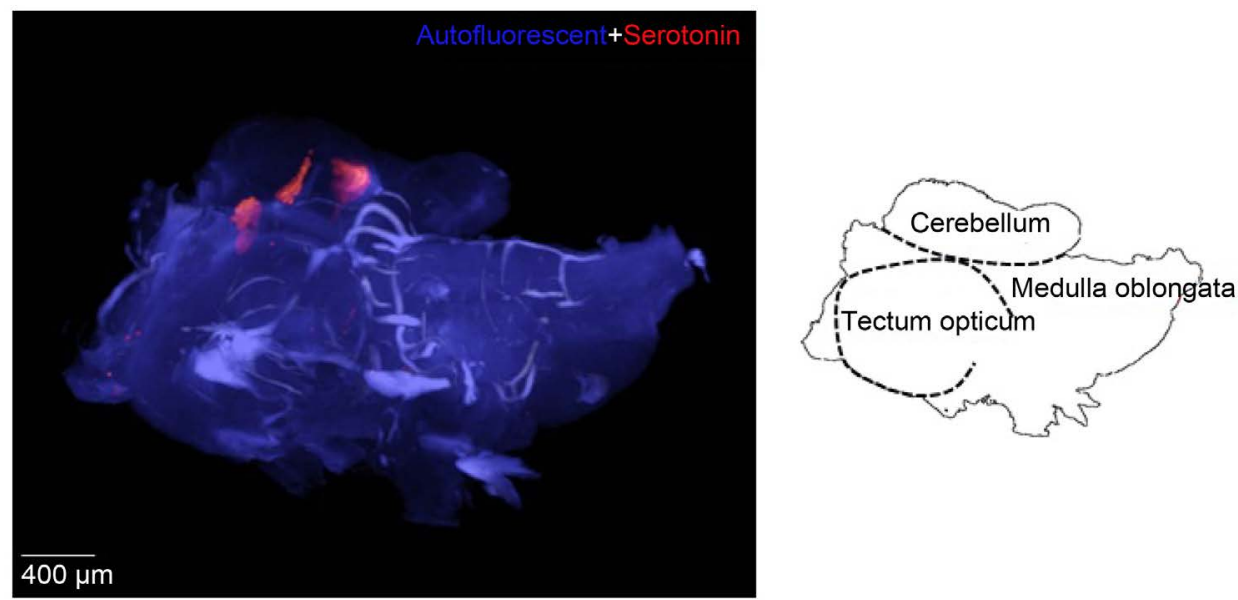

Figure 6. Detection of 5-HT in zebrafish brain by OPT. The brain structure is shown in blue (autofluorescence) while the red areas depict 5-HT-specific staining, primarily in the cerebellum. Right: sketch of structures in the zebrafish brain. 


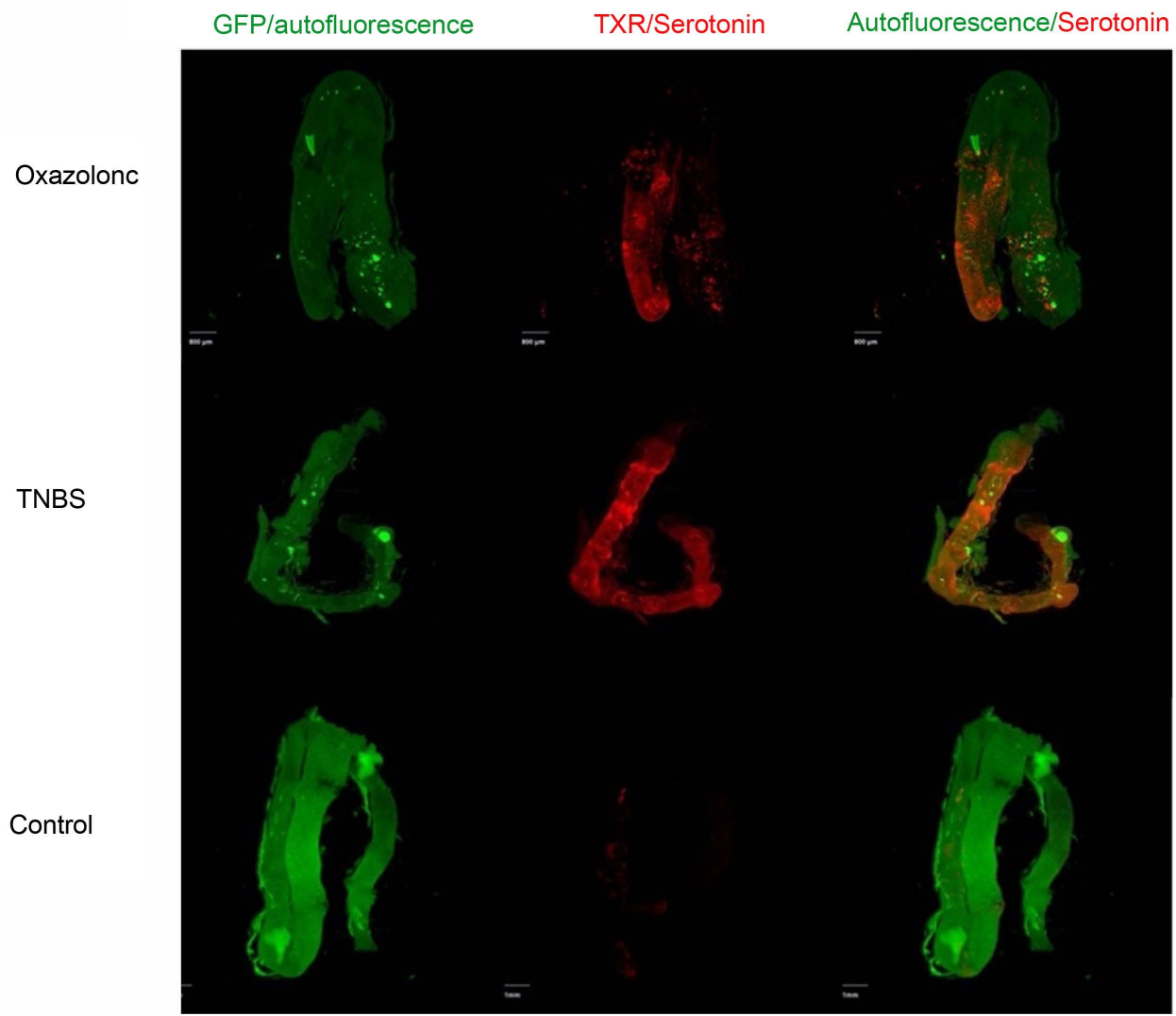

Figure 7. Detection of 5-HT in zebrafish intestine $72 \mathrm{hpi}$. Fish were exposed to either $0.6 \%$ oxazolone or $160 \mu \mathrm{m}$ TNBS, control fish received water. Green is autofluorescence, depicting intestinal structure, while red shows with specific 5-HT-stained areas.

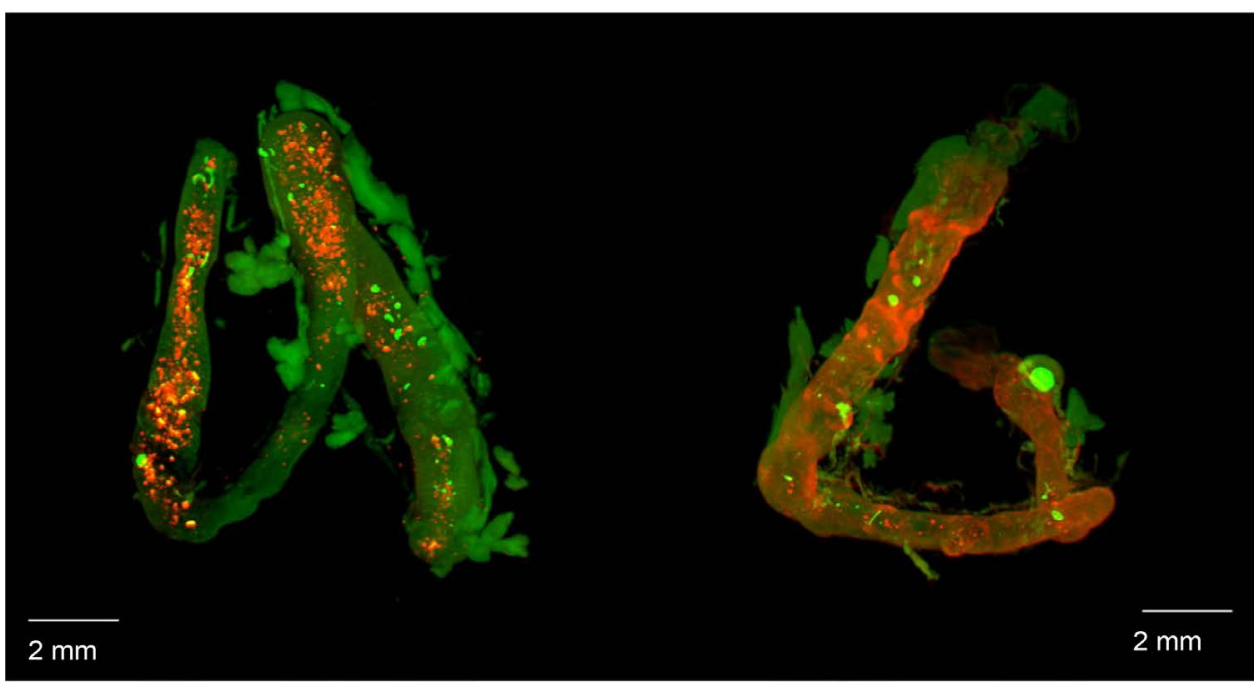

Figure 8. Left: Intestine from control fish. Right: intestine from TNBS-treated fish. Green is depicting intestinal structure; red is showing 5-HT staining.

The models were investigated using a panel of novel transcriptional markers as well as 3D-based technologies and more traditional goblet cell countings. The results confirm 
the promising use of zebrafish as a model organism for human diseases.

Adult zebrafish treated with TNBS or oxazolone showed distinct morbidity and mortality. However, the mortality observed in the TNBS-treated zebrafish in the present study was slightly lower than previously reported by Geiger et al. [10], studying a comparable zebrafish model. Brugman et al. [6] did not note reduced survival rates in adult zebrafish exposed to a low concentration $(0.2 \%)$ oxazolone which is lower that the concentration (0.6\%) used in this study.

A depletion of goblet cells in scales of both oxazolone and TNBS-treated fish were observed after $72 \mathrm{hpi}$ in the present study. In the intestine, an emptying of mucus from goblet cells was also observed in the oxazolone group, after 6 and 72 hpi. The TNBSgroup showed no fluctuations in stained goblet cell numbers when compared to controls. To our knowledge, this is the first study investigating the scale-based population of this cell type in a zebrafish colitis model. Goblet cells are modified epithelial cells capable of synthetizing and secreting a number of biomolecules, and amongst these the glycoprotein MUC2 is pivotal to maintaining mucosal stability in vertebrates [32]. Two genes, Muc 2.1 and Muc 2.2, have been identified in zebrafish and they group with the human and avian MUC2 mucin gene, but only Muc 2.2 has been found to be (weakly) expressed in skin of juvenile zebrafish [33]. Depletion of these mucus-containing cells and has been reported in intestines of patients with ulcerative colitis and in oxazolone-exposed rodent models; in contrast, Crohn's disease patients and the associated animal models usually exhibit a differentiation of the goblet cell population [13] [21] [32]. A distinct emptying of goblet cells in intestines of oxazolone-exposed adult zebrafish has been reported [6] whereas both an increase in goblet cell density [7] [11] and an unaffected goblet cell population [9] [10] have been observed in models using TNBS and larval/adult zebrafish. Goblet cells in fish have been shown to release mucins as a response to environmental factors, such as formalin [34] and ectoparasites [35], but the effect on skin goblet cells in the present study may be mediated by systemic factors such as cytokines produced in intestinal cells. The depletion of goblet cells in both intestines and scales of oxazolone-treated fish is interesting and warrants further study. From an ethical point of view, anaesthetizing the fish and removing a few scales for analysis is preferable to euthanizing the whole animal.

A number of the investigated immune genes were significantly regulated in oxazolone and TNBS-treated zebrafish. Proinflammatory cytokines are recognized as key players in the initiation and development of inflammatory bowel diseases (IBD), and amongst the most important are IL- $1 \beta$, IL- 6 and TNF- $\alpha$. These molecules are associated with both major clinical forms of IBD-Crohn's disease and ulcerative colitis- and are not restricted to a specific T-helper cell subset [2] [36]. In this study, transcript levels of IL- $1 \beta$ and TNF- $\alpha$ were significantly elevated in both colitis-groups. Previous zebrafish-based studies have reported an increase in gene expression of IL- $1 \beta$ and TNF- $\alpha$ in adult fish few hours after they had been exposed to oxazolone [6] or TNBS [10]. Similar increases have been reported using larval TNBS-models and qPCR/immunofluorescence techniques [7] [9] [11]. The role of IL-6 has not been scrutinized in colitis models 
using zebrafish until now. In other fish-based inflammation studies, IL-6 has been involved in both amplification and dampening of the immune reaction in trout head kidney macrophages [37] and was up-regulated in zebrafish skin as a response to IL- $1 \beta$ expression in a recent inflammation model [38]. Interestingly, the IL-6 gene showed no alterations of expression level compared to controls in this study. Considering the multifaceted and central role of IL-6 in a number of inflammatory conditions, including IBD [39], the results are not readily explained, but knowledge of IL-6 function and signaling is considered to be inadequate in fish at present [40]. Confirming earlier zebrafish-inflammatory studies [8] [9] [10] [41], the neutrophil-activating chemokineCxCL8 (IL-8) was significantly up-regulated in the TNBS groups after $72 \mathrm{hpi}$. In the oxazolone-exposed group, CxCL8 transcript levels were also elevated after $72 \mathrm{hpi}$, albeit at noticeably higher level than in the TNBS group. Cxcl8 is pivotal in orchestrating neutrophil influx to the site of inflammation, and gene trancripts have been detected from intestinal cells in larval zebrafish in a TNBS-model [8]. As noted by Brugman [22], mice do not possess a Cxcl8 gene that is homologous to its human counterpart CXCL8, in contrast to zebrafish. This may further support the use of zebrafish IBD-model when studying neutrophil migration.

Matrix metalloproteinases (MMPs), a family of degradative enzymes, are crucial factors in inflammatory conditions in humans [42]. In relation to colitis, MMP-9 isconsidered to be the most important protease and it is distinctly overexpressed in both forms of IBD in humans and rodent models [43] [44] [45]. Recently, Oehlers et al. [9] reported a significant increase of MMP-9 in larval zebrafish exposed to TNBS and, using adult fish; similar results have been obtained in this study. The acute-phase proteins $\mathrm{C} 3$, CRP and SAA were investigated for the first time in a zebrafish-colitis model in the present study, and significant up-regulations of the genes were detected in the intestine of both treated groups after 72 hpi. In humans, CD patients have higher levels of C3 and CRP in serum when compared to UC, and SAA is also known to be highly up-regulated in human and murine epithelial cells under inflammatory conditions [27] [46] [47].

Induction of acute-phase proteins is mediated by innate Toll-like receptors (TLRs) in mammals, which, upon stimulation by microbial factors or pathogens, release proinflammatory cytokines, facilitating the up-regulation of acute-phase proteins through their specific transcription factors [36] [48]. TLRs also activate NF- $\nprec$ b, a central transcription factor in inflammation, through activation of different adaptor proteins (e.g. the MyD88-dependent pathway), ultimately resulting in an inflammatory reaction dominated by a series of proinflammatory cytokines [49]. TLR orthologs as well as MyD88 signalling and NF- $k$ b activation have been described from larval zebrafish [50] [51]. Recently, He et al. [11] reported an increase of TLR-3, the signaling proteins MyD88 and TICAM-1(TRIF) and NF- $\kappa \mathrm{b}$ in TNBS-treated zebrafish larvae. This is in contrast with the results obtained in the present study in which only TLR-2 and TICAM-1 were significantly down- and up-regulated in the oxazolone group after $72 \mathrm{~h}$ and in the TNBS group after $6 \mathrm{hpi}$, respectively; TLR-3, MYD88 and NF- $\kappa \mathrm{b}$ were not 
significantly affected by the chemical treatment. However, He et al. [11] used larval zebrafish as opposed to adult fish in this study. It can be speculated that TLR-signaling and associated pathways are different in adult fish, which possess a fully functional adaptive ( $\mathrm{T}$-cell based) immune system.

No significant regulation of genes encoding IgM, IgZ, CD4 or CD8 genes were noted, except for a depression in IgM expression after $72 \mathrm{hpi}$ in the ethanol control group. The immunoglobulin IgZ was described in 2005 from zebrafish [52]. Later, Hu et al. [53] reported that another IgZ isotype (IgZ-2) exists in zebrafish that, in contrast to the original IgZ, was expressed in intestine (and other immune-active tissues) upon LPS provocation. Future studies should investigate expression of IgZ-2 in more detail using the present model. Genes for CD4 and CD8, co-receptors associated with T cell receptors, have been identified in zebrafish. CD4 occurs in three forms CD4-1, CD4-2 and CD4-3, andCD4-1+ leucocyte cytokine expression has recently been shown to involve central Th1 and Th2 cytokines in antigen-stimulated head kidneys [54]. A less clear differentiation occurred in the present study suggesting that cytokine-associated Th pathways may differ according to type of stimulation.

In the present study, a collective up-regulation was not seen amongst the genes associated with specific $\mathrm{T}$ cell subsets, except for Treg. Genes encoding transcription factors for the Th-1 (STAT-4 and T-bet), Th2 (STAT-6, GATA-3) and Th17 (STAT-3) pathways in mammals did not exhibit altered transcript levels in the colitis groups in zebrafish. The key Th- 1 cytokines IFN- $\gamma$ and IL-12 were not significantly regulated, whereas IL-4/13A and IL-4/13b-hallmark cytokines of the Th2 pathway-were significantly upor down regulated, respectively, after $72 \mathrm{hpi}$ in both treated groups. At the moment it is not clear if the two paralogous IL4-/13-genes in zebrafish are functionally comparable to their mammalian counterparts, but is has been suggested that IL-4/13Acorrespond to IL-4 in zebrafish [55]. In two recent studies, IL-4/13b gene expression was elevated in zebrafish and carp kidney cell lines exposed to antigens, whereas IL-4/13a expression was unaffected [54] [56]. It may be speculated that the different expression observed in the present study is associated with differential expression in different organs. IL-17A and IL-17F are secreted by Th17 cells in mammals where they induce expression of a range of important cytokines, e.g. IL-1 $\beta$, IL-6, CXCL8, and various metalloproteinases under inflammatory conditions [36]. In zebrafish, three genes-IL-17A/F-1 to IL-17A/ F-3-have been identified which are considered to be homologous to IL-17A and IL-17F in higher vertebrates [57]. The expression of all three genes have been detected in both normal and LPS-stimulated intestinal tissue in zebrafish [57], and it is difficult to explain the inconsistent results obtained in this study with only IL-17A1 being significantly up-regulated (oxazolone group, $6 \mathrm{hpi}$ ). However, the different IL-17 forms may be associated with specific pathways. The cytokine IL-22, also released by Th17 cells in mammals, has anti-inflammatory effects and stimulates wound healing [36]. In the present study, gene expression was elevated in the TNBS group after $72 \mathrm{hpi}$. Two other anti-inflammatory cytokines, IL-10 and TGF- $\beta$, were also significantly up-regulated in the TNBS group, 72 hours after exposure; TGF- $\beta$ also in the oxazolone group at the 
same time point. The anti-inflammatory effects have been documented in rodent models (reviewed in [36]) and IL-10 has also been studied in experimental zebrafish-colitis [6] [10]. In these acute inflammation models, intestinal IL-10 gene expression was elevated 5 hours after a single rectal exposure to oxazolone and TNBS, respectively, which is earlier observed than in the present study. Finally, Foxp3 transcript levels were increased after 6 hpi in both exposure-groups in the present study, and it is the only transcription factor to be significantly regulated. Given that the Treg transcription factor and its two major associated cytokines, IL-10 and TGF- $\beta$, exhibit elevated gene expression levels suggest a key involvement in chemically induced colitis in adult zebrafish in response to inflammation.

A possible explanation for the lack of gene expression of T-bet, STAT-3,-4,-6 and GATA-3 transcription factor and their associated cytokines as observed in the present study may be found in a general low expression (too low to be detected) or simply that sampling should be more frequent. The finding is perhaps not surprising, as a strong T-cell response usually is not invoked already after a few days. However, fish signaling pathways are, as noted above, not yet fully understood and it is possible that fish use alternative pathways than in mammals. Hence, the confirmative data obtained in this study is important in its own sense. In rodent models, the pathway signaling is more clear-cut; however, a mixture of Th1/Th2 signaling has been reported in oxazolonetreated mice [58]. In several genes (IFN- $\gamma$, T-bet, IL-17AF-2) a significant up-regulation was observed in the ethanol control groups only. It is important to remember that ethanol is a mild irritant in itself [6] which should be considered when evaluating inflammatory responses induced by chemicals administered in ethanol solvent.

The gene encoding S100A1, acalcium-binding protein involved in plasma membrane transport [28] was also studied experimentally. S100A1 is, in mammals, involved in regulation of cardiac contractility by regulating transport of $\mathrm{Ca}_{2}^{+}$[59]. As noted in the Methods section, it is unclear what this gene is expressing specifically in zebrafish. This gene and isoforms hereof in teleost might be evolutionary precursor genes of some of the genes in S100A family such as S100A8/A9-also known as calprotectin-which is used as a faecal biomarker for IBD [26] [27]. We have showed a distinct up-regulation of S100A1 in our two colitis models in zebrafish in the present study. This finding indicates an inflammatory affiliation of S100A1 in teleosts, but it is difficult to conclude anything based on current knowledge.

We saw an increase of 5-HT-signaling in zebrafish intestine, visualized by optical projection tomography. The brain was included as a positive control as several 5-HT signaling centers are located in this tissue [17]. Obtaining a detectable signal in brain tissue encouraged further study of the intestine. The reaction in intestinal tissue varied in strength and strong 5-HT signals was not seen in all chemically exposed fish, but, more importantly, the reaction was detected in each treatment group, suggesting an overall inflammatory response independent of colitis-inducing agent. Increased 5-HT secretion has been linked with neutrophil activity in inflamed tissues [19], a plausible scenario in our models based on the distinct up-regulation of inflammatory genes. 
Given the multifaceted role of 5-HT, it cannot be excluded that other factors such as fish anxiety or pain could have influenced the results even though fish were treated as gently as possible.

\section{Conclusion}

In conclusion, treatments with TNBS and oxazolone induced a distinct inflammatory reaction in zebrafish intestinal tissues. Mucus-producing goblet cells in skin were depleted and intestinal 5-HT (serotonin) activity increased in both chemically treated groups. A number of important pro-inflammatory molecules (e.g. IL- $1 \beta$, TNF- $\alpha$, acutephase proteins) were markedly up-regulated as were other central genes, such as the anti-inflammatory cytokines IL-10 and TGF- $\beta$. TNBS and oxazolone treatments did not lead to clear-cut Th1/Th17 and Th2-type response, indicating a CD and UC condition, respectively. However, a significant regulation was seen in the gene expression of Foxp3, the transcription factor associated with Treg, and IL-10 and TGF- $\beta$, which are central Treg cytokines. The zebrafish is useful for studying inflammatory disorders, but it cannot be excluded that different pathways are activated when compared to mammalian models. A combination of the novel gene expression techniques developed for zebrafish may, together with OPT scanning, prove as valuable tools for further description of IBD pathogenesis.

\section{Acknowledgements}

The work was funded by the Novo Nordisk-LIFE In Vivo Pharmacology Centre (LIFEPHARM) and the Villum Foundation (grant No. VKR022858). The authors wish to thank Hannah Malene Jensen and Sanaz Mazaheri for technical assistance.

\section{Author Contributions}

All authors participated in experimental design as well as analysis of data and preparation of the draft. S.H. and M.O. performed the experiments.

\section{Disclosure Statement}

The authors declare that there was no competing interests or conflict of interest.

\section{References}

[1] Kaser, A., Zeissig, S. and Blumberg, R.S. (2010) Inflammatory Bowel Disease. Annual Review of Immunology, 28, 573-621. https://doi.org/10.1146/annurev-immunol-030409-101225

[2] Strober, W. and Fuss, I. (2011) Proinflammatory Cytokines in the Pathogenesis of Inflammatory Bowel Disease. Gastroenterology, 140, 1756-1767. https://doi.org/10.1053/j.gastro.2011.02.016

[3] Carvalho, R.S., Abadom, V., Dilworth, H.P., Thompson, R., Oliva-Hemker, M. and Cuffari, C. (2006) Indeterminate Colitis: A Significant Subgroup of Pediatric IBD. Inflammatory Bowel Diseases, 12, 258-262. https://doi.org/10.1097/01.MIB.0000215093.62245.b9 
[4] Tremaine, W. (2011) Diagnosis and Treatment of Indeterminate Colitis. Gastroenterology \& Hepatology, 7, 826-828.

[5] Goldsmith, J.R. and Jobin, C. (2012) Think Small: Zebrafish as a Model System of Human Pathology. Journal of Biomedicine and Biotechnology, 2012, Article ID: 817341. https://doi.org/10.1155/2012/817341

[6] Brugman, S., et al. (2009) Oxazolone-Induced Enterocolitis in Zebrafish Depends on the Composition of the Intestinal Microbiota. Gastroenterology, 137, 1757-1767. https://doi.org/10.1053/j.gastro.2009.07.069

[7] Fleming, A., Jankowski, J. and Goldsmith, P. (2010) In Vivo Analysis of Gut Function and Disease Changes in a Zebrafish Larvae Model of Inflammatory Bowel Disease: A Feasibility Study. Inflammatory Bowel Disease, 16, 1162-1172. https://doi.org/10.1002/ibd.21200

[8] Oehlers, S.H., et al. (2010) Expression of Zebrafish Cxcl8 (Interleukin-8) and Its Receptors during Development and in Response to Immune Stimulation. Developmental and Comparative Immunology, 34, 352-359. https://doi.org/10.1016/j.dci.2009.11.007

[9] Oehlers, S.H., Flores, M.V., Okuda, K.S., Hall, C.J., Crosier, K.E. and Crosier, P.S. (2011) A Chemical Enterocolitis Model in Zebrafish Larvae That Is Dependent on Microbiota and Responsive to Pharmacological Agents. Developmental Dynamics, 240, 288-298. https://doi.org/10.1002/dvdy.22519

[10] Geiger, B.M., et al. (2013) Intestinal Up-Regulation of Melanin-Concentrating Hormone in TNBS-Induced Enterocolitis in Adult Zebrafish. PLoS ONE, 8, e83194. https://doi.org/10.1371/journal.pone.0083194

[11] He, Q., Wang, L., Wang, F. and Li, Q. (2014) The Role of Gut Microbiota in a Zebrafish Model with Chemically Induced Enterocolitis Involving Toll-Like Receptor Signaling Pathways. Zebrafish, 11, 255-264. https://doi.org/10.1089/zeb.2013.0917

[12] Thakur, P.C., Davison, J.M., Stuckenholz, C., Lu, L. and Bahary, N. (2014) Dysregulated Phosphatidylinositol Signaling Promotes Endoplasmic-Reticulum-Stress-Mediated Intestinal Mucosal Injury and Inflammation in Zebrafish. Disease Models \& Mechanisms, 7, 93106. https://doi.org/10.1242/dmm.012864

[13] Nagaoka, M. and Radi, Z.A. (2012) Pharmacologic Efficacy in Inflammatory Bowel Disease. Frontiers in Bioscience, S4, 1295-1314. https://doi.org/10.2741/s332

[14] Ohtani, M., Villumsen, K.R., Strøm, H.K. and Raida, M.K. (2014) 3D Visualization of the Initial Yersinia ruckeri Infection Route in Rainbow Trout (Oncorhynchus mykiss) by Optical Projection Tomography. PLoS ONE, 9, e89672. https://doi.org/10.1371/journal.pone.0089672

[15] Ohtani, M., Villumsen, K.R., Koppang, E.O. and Raida, M.K. (2015) Global 3D Imaging of Yersinia ruckeri Bacterin Uptake in Rainbow Trout Fry. PLoS ONE, 10, e0117263. https://doi.org/10.1371/journal.pone.0117263

[16] Mawe, G.M. and Hoffman, J.M. (2013) Serotonin Signalling in the Gut-Functions, Dysfunctions and Therapeutic Targets. Nature Reviews Gastroenterology and Hepatology, 10, 473-486. https://doi.org/10.1038/nrgastro.2013.105

[17] Lillesaar, C. (2011) The Serotonergic System in Fish. Journal of Chemical Neuroanatomy, 41, 294-308. https://doi.org/10.1016/j.jchemneu.2011.05.009

[18] Simonson, L.W., Ganz, J., Melancon, E. and Eisen, J.S. (2013) Characterization of Enteric Neurons in Wild-Type and Mutant Zebrafish Using Semi-Automated Cell Counting and Co-Expression Analysis. Zebrafish, 10, 147-153. https://doi.org/10.1089/zeb.2012.0811

[19] Duerschmied, D., et al. (2013) Platelet Serotonin Promotes the Recruitment of Neutrophils to Sites of Acute Inflammation in Mice. Blood, 121, 1008-1015. 
https://doi.org/10.1182/blood-2012-06-437392

[20] Xu, Z., et al. (2013) Teleost Skin, an Ancient Mucosal Surface That Elicits Gut-Like Immune Responses. Proceedings of the National Academy of Sciences, 110, 13097-13102. https://doi.org/10.1073/pnas.1304319110

[21] Gersemann, M., et al. (2009) Differences in Goblet Cell Differentiation between Crohn's Disease and Ulcerative Colitis. Differentiation, 77, 84-94.

https://doi.org/10.1016/j.diff.2008.09.008

[22] Brugman, S. (2016) The Zebrafish as a Model to Study Intestinal Inflammation. Developmental and Comparative Immunology, 64, 82-92. https://doi.org/10.1016/j.dci.2016.02.020

[23] Buchmann, K. (2007) An Introduction to Fish Parasitological Methods-Classical and Molecular Methods. Biofolia, Frederiksberg.

[24] Untergasser, A., Nijveen, H., Rao, X., Bisseling, T., Geurts, R. and Leunissen, J.A.M. (2007) Primer3Plus, an Enhanced Web Interface to Primer3. Nucleic Acids Research, 35, W71W74. https://doi.org/10.1093/nar/gkm306

[25] Ruijter, J.M., et al. (2009) Amplification Efficiency: Linking Baseline and Bias in the Analysis of Quantitative PCR Data. Nucleic Acids Research, 37, e45. https://doi.org/10.1093/nar/gkp045

[26] Smith, L.A. and Gaya, D.R. (2012) Utility of Faecal Calprotectin Analysis in Adult Inflammatory Bowel Disease. World Journal of Gastroenterology, 18, 6782-6789. https://doi.org/10.3748/wjg.v18.i46.6782

[27] Viennois, E., Zhao, Y. and Merlin, D. (2015) Biomarkers of Inflammatory Bowel Disease: From Classical Laboratory Tools to Personalized Medicine. Inflammatory Bowel Diseases, 21, 2467-2474. https://doi.org/10.1097/mib.0000000000000444

[28] Rescher, U. and Gerke, V. (2008) S100A1/P11: Family, Friends and Functions. European Journal of Physiology, 455, 575-582.

[29] Haarder, S., Kania, P.W., Bahlool, Q.Z.M. and Buchmann, K. (2013) Expression of Immune Relevant Genes in Rainbow Trout Following Exposure to Live Anisakis simplex Larvae. Experimental Parasitology, 135, 564-569. https://doi.org/10.1016/j.exppara.2013.09.011

[30] Alanentalo, T., et al. (2007) Tomographic Molecular Imaging and 3D Quantification within Adult Mouse Organs. Nature Methods, 4, 31-33. https://doi.org/10.1038/nmeth985

[31] Livak, K.J. and Schmittgen, T.D. (2001) Analysis of Relative Gene Expression Data Using Real-Time Quantitative PCR and the 2(-Delta Delta C(T)) Method. Methods, 25, 402-408. https://doi.org/10.1006/meth.2001.1262

[32] Kim, Y.S. and Ho, S.B. (2010) Intestinal Goblet Cells in Health and Disease: Recent Insights and Progress. Current Gastroenterology Reports, 12, 319-330. https://doi.org/10.1007/s11894-010-0131-2

[33] Jevtov, I., Samuelsson, T., Yao, G., Amsterdam, A. and Ribbeck, K. (2014) Zebrafish as a Model to Study Live Mucus Physiology. Scientific Reports, 4, Article No. 6653. https://doi.org/10.1038/srep06653

[34] Buchmann, K., Bresciani, J. and Jappe, C. (2004) Effects of Formalin Treatment on Epithelial Structure and Mucous Cell Densities in Rainbow Trout, Oncorhynchus mykiss (Walbaum), Skin. Journal of Fish Diseases, 27, 99-104. https://doi.org/10.1111/j.1365-2761.2003.00519.x

[35] Esteban, M.A. and Cerezuela, R. (2015) Fish Mucosal Immunity: Skin. In: Beck and Peatman, Eds., Mucosal Health in Aquaculture, Academic Press, Cambridge, 67-92.

[36] Neurath, M.F. (2014) Cytokines in Inflammatory Bowel Disease. Nature Reviews Immunology, 14, 328-342. https://doi.org/10.1038/nri3661 
[37] Costa, M.M., Maehr, T., Diaz-Rosales, P., Secombes, C.J. and Wang, T (2011) Bioactivity Studies of Rainbow Trout (Oncorhynchus mykiss) Interleukin-6: Effects on Macrophage Growth and Antimicrobial Peptide Gene Expression. Molecular Immunology, 48, 19031916. https://doi.org/10.1016/j.molimm.2011.05.027

[38] Yan, B., et al. (2014) Il-1 $\beta$ and Reactive Oxygen Species Differentially Regulate Neutrophil Directional Migration and Basal Random Motility in a Zebrafish Injury-Induced Inflammation Model. Journal of Immunology, 192, 5998-6008.

https://doi.org/10.4049/jimmunol.1301645

[39] Mudter, J. and Neurath, M.F. (2007) IL-6 Signaling in Inflammatory Bowel Disease: Pathophysiological Role and Clinical Relevance. Inflammatory Bowel Diseases, 13, 1016-1023. https://doi.org/10.1002/ibd.20148

[40] Reyes-Cerpa, S., Maisey, K., Reyes-López, F., Toro-Ascuy, D., Sandino, A.M. and Imarai, M. (2012) Fish Cytokines and Immune Response. In: Turker, H., Ed., New Advances and Contributions to Fish Biology, InTech, Rijeka, 8-9. https://doi.org/10.5772/53504

[41] Brugman, S., Witte, M., Scholman, R.C., Klein, M.R., Boes, M. and Nieuwenhuis, E.E. (2014) T Lymphocyte-Dependent and -Independent Regulation of Cxcl8 Expression in Zebrafish Intestines. Journal of Immunology, 192, 484-491. https://doi.org/10.4049/jimmunol.1301865

[42] Ravi, A., Garg, P. and Sitaraman, S.V. (2007) Matrix Metalloproteinases in Inflammatory Bowel Disease: Boon or Bane? Inflammatory Bowel Diseases, 13, 97-107. https://doi.org/10.1002/ibd.20011

[43] Baugh, M.D., et al. (1999) Matrix Metalloproteinase Levels Are Elevated in Inflammatory Bowel Disease. Gastroenterology, 117, 814-822. https://doi.org/10.1016/S0016-5085(99)70339-2

[44] Tarlton, J.F., et al. (2000) The Role of Up-Regulated Serine Proteases and Matrix Metalloproteinases in the Pathogenesis of a Murine Model of Colitis. American Journal of Pathology, 157, 1927-1935. https://doi.org/10.1016/S0002-9440(10)64831-6

[45] Meijer, M.J.W., et al. (2007) Increased Mucosal Matrix Metalloproteinase-1, -2, -3 and -9 Activity in Patients with Inflammatory Bowel Disease and the Relation with Crohn's Disease Phenotype. Digestive and Liver Disease, 39, 733-739. https://doi.org/10.1016/j.dld.2007.05.010

[46] Bene, L., et al. (2003) High Normal Serum Levels of C3 and C1 Inhibitor, Two Acute-Phase Proteins Belonging to the Complement System, Occur More Frequently in Patients with Crohn's Disease than Ulcerative Colitis. Digestive Diseases and Sciences, 48, 1186-1192. https://doi.org/10.1023/A:1023793502456

[47] Jijon, H.B., Madsen, K.L., Walker, J.W., Allard, B. and Jobin, C. (2005) Serum Amyloid A Activates NF- $\kappa$ B and Proinflammatory Gene Expression in Human and Murine Intestinal Epithelial Cells. European Journal of Immunology, 35, 718-726. https://doi.org/10.1002/eji.200425688

[48] Poli, V. (1998) The Role of C/EBP Isoforms in the Control of Inflammatory and Native Immunity Functions. Journal of Biological Chemistry, 273, 29279-29282. https://doi.org/10.1074/jbc.273.45.29279

[49] Akira, S. and Takeda, K. (2004) Toll-Like Receptor Signaling. Nature Reviews Immunology, 4, 499-511. https://doi.org/10.1038/nri1391

[50] Kanther, M., et al. (2011) Microbial Colonization Induces Dynamic Temporal and Spatial Patterns of NF- $\kappa$ B Activation in the Zebrafish Digestive Tract. Gastroenterology, 141, $197-$ 207. https://doi.org/10.1053/j.gastro.2011.03.042 
[51] Van der Vaart, M., van Soest, J.J., Spaink, H.P. and Meijer, A.P. (2013) Functional Analysis of a Zebrafish MyD88 Mutant Identifies Key Transcriptional Components of the Innate Immune System. Disease Models and Mechanisms, 6, 841-854.

https://doi.org/10.1242/dmm.010843

[52] Danilova, N., Bussmann, J., Jekosch, K. and Steiner, L.A. (2005) The Immunoglobulin Heavy-Chain Locus in Zebrafish: Identification and Expression of a Previously Unknown Isotype, Immunoglobulin Z. Nature Immunology, 6, 295-302.

https://doi.org/10.1038/ni1166

[53] Hu, Y.L., Xiang, L.X. and Shao, J.Z. (2010) Identification and Characterization of a Novel Immunoglobulin Z Isotype in Zebrafish: Implications for a Distinct B Cell Receptor in Lower Vertebrates. Molecular Immunology, 47, 738-746. https://doi.org/10.1016/j.molimm.2009.10.010

[54] Yoon, S., et al. (2015) First Demonstration of Antigen Induced Cytokine Expression by CD4- $1^{+}$Lymphocytes in a Poikilotherm: Studies in Zebrafish (Danio rerio). PLoS ONE, 10, e0126378. https://doi.org/10.1371/journal.pone.0126378

[55] Zhu, L.-Y., Pan, P.-P., Fang, W., Shao, J.-Z. and Xian, L.-X. (2012) Essential Role of IL-4 and IL-4R $\alpha$ Interaction in Adaptive Immunity of Zebrafish: Insight into the Origin of Th2-Like Regulatory Mechanism in Ancient Vertebrates. Journal of Immunology, 188, 5571-5584. https://doi.org/10.4049/jimmunol.1102259

[56] Yamaguchi, T., Katakura, F., Someya, K., Dijkstra, J.M., Moritomo, T. and Nakanishi, T. (2013) Clonal Growth of Carp (Cyprinus carpio) T Cells in Vitro: Long-Term Proliferation of Th2-Like Cells. Fish \& Shellfish Immunology, 34, 433-442. https://doi.org/10.1016/j.fsi.2012.11.005

[57] Gunimaladevi, I., Savan, R. and Sakai, M. (2006) Identification, Cloning and Characterization of Interleukin-17 and Its Family from Zebrafish. Fish and Shellfish Immunology, 21, 393-403. https://doi.org/10.1016/j.fsi.2006.01.004

[58] Iijima, H., et al. (2004) Specific Regulation of T Helper Cell 1-Mediated Murine Colitis by CEACAM1. Journal of Experimental Medicine, 199, 471-482. https://doi.org/10.1084/jem.20030437

[59] Most, P., et al. (2001) S100A1: A Regulator of Myocardial Contractility. Proceedings of the National Academy of Sciences, 98, 13889-13894. https://doi.org/10.1073/pnas.241393598 


\section{Supplementary Material}

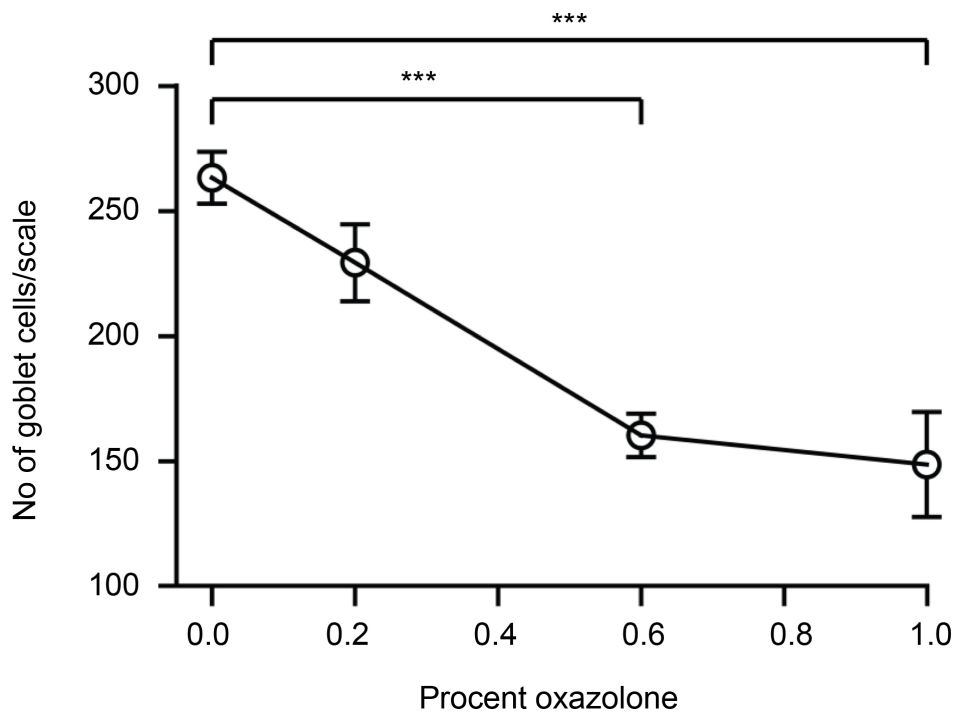

Figure S1. Number of Alcian-Blue stained goblet cells in scales of zebrafish exposed to three different concentrations of oxazolone $(0.2 \%, 0.6 \%, 1.0 \%)$. Fish were euthanized 72 hpi. 3 scales were investigated from 3 fish per concentration group. 
Table S1. Primer and probe information for immune genes expressed in the zebrafish intestine in the present study. The C3 assay is amplifying 3 isoforms ( $a, b$ and $c)$.

\begin{tabular}{|c|c|c|c|c|}
\hline Gene name & Prim & probes $\left(5^{\prime}-\right.$ to $\left.-3^{\prime}\right)$ & Length & Accession \\
\hline$\beta$-actin & $\begin{array}{l}\text { Forward primer: } \\
\text { Reverse primer: } \\
\text { Probe: }\end{array}$ & $\begin{array}{l}\text { ccatccttcttgggtatgga } \\
\text { acaggtccttacggatgtcg } \\
\text { tgcggtatccacgagaccacc }\end{array}$ & 91 & BC154531 \\
\hline $\mathrm{C} 3 \mathrm{abc}$ & $\begin{array}{l}\text { Forward primer: } \\
\text { Reverse primer: } \\
\text { Probe: }\end{array}$ & $\begin{array}{l}\text { tgctgttcttctctcctcagc } \\
\text { wgakgaacccactctcagca } \\
\text { ctcacactgtgtgaccegctat }\end{array}$ & 88 & $\begin{array}{c}\text { NM_131242 } \\
\text { NM_131243 } \\
\text { NM_001037236 }\end{array}$ \\
\hline $\mathrm{CD} 4$ & $\begin{array}{l}\text { Forward primer: } \\
\text { Reverse primer: } \\
\text { Probe: }\end{array}$ & $\begin{array}{l}\text { ccagactggagccaagagac } \\
\text { cagtgcagctccacatcact } \\
\text { cctgcgcacagtcagggaaa }\end{array}$ & 133 & EF601915 \\
\hline $\mathrm{CD} 8 \alpha$ & $\begin{array}{l}\text { Forward primer: } \\
\text { Reverse primer: } \\
\text { Probe: }\end{array}$ & $\begin{array}{l}\text { tcggaggttgtggacttttc } \\
\text { taatggtggggacatcgtct } \\
\text { cgttctgctgatcgcaacca }\end{array}$ & 88 & BC114236 \\
\hline CRP & $\begin{array}{l}\text { Forward primer: } \\
\text { Reverse primer: } \\
\text { Probe: }\end{array}$ & $\begin{array}{l}\text { tcgatagggaggtcatcctg } \\
\text { gcagcagggtctttctgact } \\
\text { gatgcagcgtttttccggct }\end{array}$ & 163 & JF772178 \\
\hline ELF1 $\alpha$ & $\begin{array}{l}\text { Forward primer: } \\
\text { Reverse primer: } \\
\text { Probe: }\end{array}$ & $\begin{array}{l}\text { gaacgacccacccatggagg } \\
\text { tgatgacctgagcgttgaag } \\
\text { gaacgacccacccatggagg }\end{array}$ & 158 & AY422992 \\
\hline FoxP3 & $\begin{array}{l}\text { Forward primer: } \\
\text { Reverse primer: } \\
\text { Probe: }\end{array}$ & $\begin{array}{c}\text { gacttctgcaacctgcatca } \\
\text { cgtatcatggaggcgtaggt } \\
\text { gagagagcagcaactgaagcgc }\end{array}$ & 181 & FM881778 \\
\hline GATA-3 & $\begin{array}{l}\text { Forward primer: } \\
\text { Reverse primer: } \\
\text { Probe: }\end{array}$ & $\begin{array}{l}\text { tacgtgtcccgcttaaaacc } \\
\text { tgaaggggcaatgaagaaag } \\
\text { ggccttcactttcgcctgct }\end{array}$ & 81 & BC162389 \\
\hline $\operatorname{IgM}$ & $\begin{array}{l}\text { Forward primer: } \\
\text { Reverse primer: } \\
\text { Probe: }\end{array}$ & $\begin{array}{l}\text { tgcagttctggttctgatgg } \\
\text { tgcacaaaatcgctcaaatc } \\
\text { aatcaccctcggctgcttgg }\end{array}$ & 122 & AY643753 \\
\hline IgZ & $\begin{array}{l}\text { Forward primer: } \\
\text { Reverse primer: } \\
\text { Probe: }\end{array}$ & $\begin{array}{l}\text { attggatgtctggcctctga } \\
\text { aatgctgggtgacgtttttc } \\
\text { tgcacaaaatcgctcaaatc }\end{array}$ & 91 & AY643750 \\
\hline IL10 & $\begin{array}{l}\text { Forward primer: } \\
\text { Reverse primer: } \\
\text { Probe: }\end{array}$ & $\begin{array}{c}\text { cttgccaaaatccctttgaa } \\
\text { atcaagctcccccatagctt } \\
\text { tgaaaagatgaaggaaaaggggg }\end{array}$ & 92 & BC163038 \\
\hline IL12 & $\begin{array}{l}\text { Forward primer: } \\
\text { Reverse primer: } \\
\text { Probe: }\end{array}$ & $\begin{array}{l}\text { agcaggacttgtttgctggt } \\
\text { tccactgcgctgaagttaga } \\
\text { taactcgtcctgctcggccc }\end{array}$ & 145 & $\mathrm{AB} 183001$ \\
\hline IL17AF1 & $\begin{array}{c}\text { Forward primer: } \\
\text { Reverse primer: } \\
\text { Probe: }\end{array}$ & $\begin{array}{l}\text { gctttcttatggtggcttgc } \\
\text { gccggtatgaatgatctgct } \\
\text { atcattcggtgctgaggggg }\end{array}$ & 123 & AB195256 \\
\hline IL17AF2 & $\begin{array}{c}\text { Forward primer: } \\
\text { Reverse primer: } \\
\text { Probe: }\end{array}$ & $\begin{array}{l}\text { tcaatctgaggacggaaagg } \\
\text { gctccatctcctgtttcagc } \\
\text { catcttgcccactggtgtgga }\end{array}$ & 215 & NM_001020798 \\
\hline
\end{tabular}


Continued

\begin{tabular}{|c|c|c|c|c|}
\hline IL17AF3 & $\begin{array}{l}\text { Forward primer: } \\
\text { Reverse primer: } \\
\text { Probe: }\end{array}$ & $\begin{array}{c}\text { ggctgcacatgtgttttacc } \\
\text { caatgtgattcgttttcaggct } \\
\text { cagcgcctatagaaataatcactccg }\end{array}$ & 250 & AB195260 \\
\hline $\operatorname{IL} 1 \beta$ & $\begin{array}{l}\text { Forward primer: } \\
\text { Reverse primer: } \\
\text { Probe: }\end{array}$ & $\begin{array}{l}\text { cgctccacatctcgtactca } \\
\text { atacgcggtgctgataaacc } \\
\text { gaaggagaccggcagctcca }\end{array}$ & 166 & ВC098597 \\
\hline IL22 & $\begin{array}{l}\text { Forward primer: } \\
\text { Reverse primer: } \\
\text { Probe: }\end{array}$ & $\begin{array}{l}\text { ggattacgccaaaggtgaaa } \\
\text { cgagcacagcaaagcaataa } \\
\text { cgacatcgaggaacaacggtg }\end{array}$ & 187 & NM_001020792 \\
\hline IL23 & $\begin{array}{l}\text { Forward primer: } \\
\text { Reverse primer: } \\
\text { Probe: }\end{array}$ & $\begin{array}{l}\text { attaccgacctgccagtgac } \\
\text { ttcaggaggtggccagtaac } \\
\text { aaatgccgaacagatcgcca }\end{array}$ & 212 & FN869917 \\
\hline IL4/13A & $\begin{array}{l}\text { Forward primer: } \\
\text { Reverse primer: } \\
\text { Probe: }\end{array}$ & $\begin{array}{l}\text { gtcaggctgaggaggagatg } \\
\text { agcagcgtgactcctgatct } \\
\text { ctggcctgtccggtgtcaaa }\end{array}$ & 155 & AB375404 \\
\hline IL4/13B & $\begin{array}{l}\text { Forward primer: } \\
\text { Reverse primer: } \\
\text { Probe: }\end{array}$ & $\begin{array}{c}\text { aactctctgccaagcaggaa } \\
\text { aaacgctgcagtttccagtc } \\
\text { gagacagctgaatgcttatgcagca }\end{array}$ & 113 & AB375405 \\
\hline IL6 & $\begin{array}{l}\text { Forward primer: } \\
\text { Reverse primer: } \\
\text { Probe: }\end{array}$ & $\begin{array}{l}\text { agaccgctgcctgtctaaaa } \\
\text { caacttctccagcgtgatga } \\
\text { tccgcatggactcgcaagac }\end{array}$ & 293 & JN698962 \\
\hline IL8 & $\begin{array}{l}\text { Forward primer: } \\
\text { Reverse primer: } \\
\text { Probe: }\end{array}$ & $\begin{array}{c}\text { gatctgtctggacccctctg } \\
\text { gggcattcatggttttctgt } \\
\text { ccatgggttaagaagatcattgatagg }\end{array}$ & 79 & XM_001342570 \\
\hline INF $\gamma$ & $\begin{array}{l}\text { Forward primer: } \\
\text { Reverse primer: } \\
\text { Probe: }\end{array}$ & $\begin{array}{l}\text { tatgggcgatcaaggaaaac } \\
\text { ctttagcctgccgtctcttg } \\
\text { cgatcgtccagcgaaaggct }\end{array}$ & 129 & $\mathrm{AB} 158361$ \\
\hline Mmp9 & $\begin{array}{l}\text { Forward primer: } \\
\text { Reverse primer: } \\
\text { Probe: }\end{array}$ & $\begin{array}{c}\text { acagggagacgctcattttg } \\
\text { tgttccctcaaacaggaagg } \\
\text { cggtaatgctgagggtgcaatgtgt }\end{array}$ & 124 & BC160656 \\
\hline Myd88 & $\begin{array}{l}\text { Forward primer: } \\
\text { Reverse primer: } \\
\text { Probe: }\end{array}$ & $\begin{array}{l}\text { tgatgatccacagggactga } \\
\text { gagatgaccaccaccatcct } \\
\text { cacatgcgtgtggaccatcg }\end{array}$ & 222 & NM_212814 \\
\hline NFkB & $\begin{array}{l}\text { Forward primer: } \\
\text { Reverse primer: } \\
\text { Probe: }\end{array}$ & $\begin{array}{l}\text { caggatttggacaaygaggt } \\
\text { ccagttccctccaaggtaca } \\
\text { tgagcaagctgtgtgggattct }\end{array}$ & 76 & BC122885 \\
\hline RP13a & $\begin{array}{l}\text { Forward primer: } \\
\text { Reverse primer: } \\
\text { Probe: }\end{array}$ & $\begin{array}{l}\text { tcccagctgctctcaagatt } \\
\text { acttccagccaacttcatgg } \\
\text { cacacgcaaatttgccetgc }\end{array}$ & 87 & NM_212784 \\
\hline S100A1 & $\begin{array}{l}\text { Forward primer: } \\
\text { Reverse primer: } \\
\text { Probe: }\end{array}$ & $\begin{array}{c}\text { gcagaggggaactcatcaac } \\
\text { cccaccacaagagacacaaa } \\
\text { cagctgatggagaaagagctggc }\end{array}$ & 98 & BC163954 \\
\hline STAT3 & $\begin{array}{l}\text { Forward primer: } \\
\text { Reverse primer: } \\
\text { Probe: }\end{array}$ & $\begin{array}{l}\text { agggaggaatcacattcacg } \\
\text { ggcgacactaggatgttggt } \\
\text { ccagattcagtcggttgaaccg }\end{array}$ & 160 & NM_131479 \\
\hline
\end{tabular}




\section{Continued}

\begin{tabular}{|c|c|c|c|c|}
\hline STAT4 & $\begin{array}{c}\text { Forward primer: } \\
\text { Reverse primer: } \\
\text { Probe: }\end{array}$ & $\begin{array}{l}\text { tatgagagcgatcccattcc } \\
\text { cctgaccttggtggtgaact } \\
\text { ttgtggtggagaagcagccc }\end{array}$ & 174 & NM_001004510 \\
\hline STAT6 & $\begin{array}{c}\text { Forward primer: } \\
\text { Reverse primer: } \\
\text { Probe: }\end{array}$ & $\begin{array}{l}\text { taaagagctggcgtcgaaat } \\
\text { tccctgttgtccacatcaaa } \\
\text { gccagctggatagaggggca }\end{array}$ & 193 & BC162530 \\
\hline SAA & $\begin{array}{c}\text { Forward primer: } \\
\text { Reverse primer: } \\
\text { Probe: }\end{array}$ & $\begin{array}{l}\text { cttgctgtgctggtgatgtt } \\
\text { cttccaattggcctctttca } \\
\text { cgctggaggtgcaaaggaca }\end{array}$ & 129 & BC081487 \\
\hline T-bet & $\begin{array}{c}\text { Forward primer: } \\
\text { Reverse primer: } \\
\text { Probe: }\end{array}$ & $\begin{array}{l}\text { aaatccaggagcatggacag } \\
\text { tgagactggatgtgggtttg } \\
\text { tggttttcctattggaaggcgg }\end{array}$ & 86 & AM942761 \\
\hline TGF $\beta$ & $\begin{array}{c}\text { Forward primer: } \\
\text { Reverse primer: } \\
\text { Probe: }\end{array}$ & $\begin{array}{l}\text { tgcgcaagctttacattgac } \\
\text { aggaccccatgcagtagttg } \\
\text { tggatccacaagcccaaggg }\end{array}$ & 93 & AY178450 \\
\hline Ticam1/TRIF & $\begin{array}{c}\text { Forward primer: } \\
\text { Reverse primer: } \\
\text { Probe: }\end{array}$ & $\begin{array}{l}\text { caaggatagcagggttggaa } \\
\text { ttgtcgcacaaactctcctg } \\
\text { tcgcaagaattttcgccattttg }\end{array}$ & 162 & $\mathrm{BC} 134858$ \\
\hline TLR2 & $\begin{array}{c}\text { Forward primer: } \\
\text { Reverse primer: } \\
\text { Probe: }\end{array}$ & $\begin{array}{l}\text { tgtctcccaccctgaaactc } \\
\text { gccactctcctatcccaaca } \\
\text { cctccacgaccgatcaagcc }\end{array}$ & 227 & AY388399 \\
\hline TLR3 & $\begin{array}{c}\text { Forward primer: } \\
\text { Reverse primer: } \\
\text { Probe: }\end{array}$ & $\begin{array}{l}\text { aaagggctacgtttggtgtg } \\
\text { gttggtggagttcagccatt } \\
\text { tcgcaagaattttcgccattttg }\end{array}$ & 119 & BC107955 \\
\hline TNF- $\alpha$ & $\begin{array}{c}\text { Forward primer: } \\
\text { Reverse primer: } \\
\text { Probe: }\end{array}$ & $\begin{array}{l}\text { gcgcttttctgaatcctacg } \\
\text { aagtgctgtggtcgtgtctg } \\
\text { tgcacgcaggagcctgaatc }\end{array}$ & 169 & AY427649 \\
\hline
\end{tabular}


Table S2. Expression of immune genes in zebrafish intestine 6 and 72 hpi after exposure to ethanol, TNBS or oxazolone. Data are presented as fold change with standard error (fold change $\pm \mathrm{SE}$ ), compared to values from control fish. Differences are considered significant at $p<0.05$ $\left.\left.{ }^{*}\right) . p<0.01{ }^{* *}\right)$. NA: signifies the failure to detect the expression of the genes at the designated time points below.

\begin{tabular}{|c|c|c|c|c|c|c|}
\hline & \multicolumn{2}{|c|}{ Ethanol } & \multicolumn{2}{|c|}{ TNBS } & \multicolumn{2}{|c|}{ Oxazolone } \\
\hline & $6 \mathrm{hpi}$ & $72 \mathrm{hpi}$ & $6 \mathrm{hpi}$ & $72 \mathrm{hpi}$ & $6 \mathrm{hpi}$ & $72 \mathrm{hpi}$ \\
\hline IL- $1 \beta$ & $1.2 \pm 0.2$ & $-1.2 \pm 0.2$ & $7.2 \pm 15.5^{*}$ & $10.9 \pm 12.7^{* *}$ & $2.9 \pm 3.2^{*}$ & $9.1 \pm 8.4^{* *}$ \\
\hline IL-4/13a & $1.5 \pm 0.3$ & $-2.2 \pm 0.2^{\star}$ & $-1.9 \pm 0.6$ & $-2.6 \pm 0.3^{*}$ & $-1.5 \pm 0.4$ & $-3.1 \pm 0.1^{\star *}$ \\
\hline IL-4/13b & $2.3 \pm 0.8$ & $1.1 \pm 0.3$ & $-1.2 \pm 0.2$ & $2.0 \pm 0.3^{*}$ & $-1.0 \pm 0.5$ & $4.0 \pm 1.5^{* *}$ \\
\hline IL-6 & NA & NA & NA & NA & NA & NA \\
\hline IL-8 & $-1.4 \pm 0.2$ & $1.2 \pm 0.7$ & $1.2 \pm 0.9$ & $4.4 \pm 3.8^{*}$ & $1.3 \pm 1.2$ & $13.8 \pm 27.7^{\star *}$ \\
\hline IL-10 & $1.4 \pm 0.4$ & $2.1 \pm 0.7^{*}$ & $1.5 \pm 0.6$ & $3.3 \pm 0.7^{* *}$ & $2.3 \pm 0.9$ & $1.7 \pm 0.9$ \\
\hline IL-12 & $1.8 \pm 0.4$ & $1.7 \pm 1.1$ & $1.4 \pm 2.0$ & $1.2 \pm 0.5$ & $1.2 \pm 0.6$ & $1.1 \pm 0.8$ \\
\hline IL-17A1 & $1.3 \pm 0.3$ & $-1.3 \pm 0.1$ & $-1.4 \pm 0.2$ & $1.7 \pm 0.3$ & $2.4 \pm 0.7^{* *}$ & $-3.6 \pm 0.1^{\star *}$ \\
\hline IL-17A2 & $1.7 \pm 2.0$ & $4.0 \pm 13.6^{*}$ & $-1.1 \pm 14.3$ & $-1.5 \pm 0.3$ & $-6.2 \pm 0.3$ & $3.6 \pm 9.7$ \\
\hline IL-17A3 & $1.1 \pm 0.3$ & $1.1 \pm 0.6$ & $-6.6 \pm 0.2^{*}$ & $1.3 \pm 0.4$ & $1.1 \pm 0.7$ & $-1.4 \pm 0.7$ \\
\hline IL-22 & $2.0 \pm 0.2$ & $1.0 \pm 0.5$ & $1.7 \pm 1.2$ & $2.7 \pm 0.8^{* *}$ & $-1.4 \pm 0.8$ & $1.3 \pm 1.3$ \\
\hline IL-23 & NA & NA & NA & $\mathrm{NA}$ & NA & NA \\
\hline IFN-g & $2.4 \pm 0.8^{*}$ & $1.1 \pm 0.2$ & $1.5 \pm 0.8$ & $1.8 \pm 0.4$ & $-1.4 \pm 0.1$ & $1.8 \pm 0.7$ \\
\hline TNF- $\alpha$ & $1.7 \pm 0.6$ & $-1.2 \pm 0.4$ & $2.1 \pm 0.7^{*}$ & $2.3 \pm 1.0^{*}$ & $2.6 \pm 1.1^{*}$ & $4.8 \pm 8.8^{*}$ \\
\hline TGF- $\beta$ & $-1.2 \pm 0.1$ & $-1.2 \pm 0.1$ & $1.2 \pm 0.4$ & $2.3 \pm 0.3^{* *}$ & $1.2 \pm 0.1$ & $2.4 \pm 0.4^{\star *}$ \\
\hline $\mathrm{mmp} 9$ & $-1.4 \pm 0.5$ & $-1.4 \pm 0.2$ & $3.3 \pm 1.5^{*}$ & $19.8 \pm 40.0^{* *}$ & $3.2 \pm 0.4^{* *}$ & $29.2 \pm 46.2^{* *}$ \\
\hline IgM & $1.3 \pm 0.4$ & $-2.8 \pm 0.5^{*}$ & $-1.4 \pm 0.3$ & $-1.6 \pm 0.5$ & $1.2 \pm 0.4$ & $1.2 \pm 0.3$ \\
\hline $\operatorname{IgZ}$ & $2.0 \pm 0.4$ & $1.2 \pm 0.5$ & $2.5 \pm 1.0$ & $2.4 \pm 0.7$ & $4.1 \pm 0.4$ & $-1.9 \pm 0.7$ \\
\hline $\mathrm{CD} 4$ & $1.9 \pm 0.4$ & $1.0 \pm 0.2$ & $-1.3 \pm 0.2$ & $-1.6 \pm 0.3$ & $1.4 \pm 0.2$ & $-1.3 \pm 0.2$ \\
\hline CD8 & $-3.7 \pm 0.6$ & $-3.3 \pm 1.5$ & $-3.0 \pm 0.4$ & $-3.0 \pm 0.9$ & $-1.0 \pm 1.7$ & $-1.4 \pm 0.7$ \\
\hline $\mathrm{C} 3$ & $-1.3 \pm 0.2$ & $-1.2 \pm 0.2$ & $-2.4 \pm 0.2^{*}$ & $6.4 \pm 2.2^{* *}$ & $-2.4 \pm 0.2$ & $3.4 \pm 1.3^{*}$ \\
\hline CRP & $-1.3 \pm 3.2$ & $-1.3 \pm 0.4$ & $2.9 \pm 10.0$ & $37.6 \pm 22.0^{* *}$ & $-2.6 \pm 0.6$ & $25.8 \pm 9.8^{* *}$ \\
\hline SAA & $1.2 \pm 0.4$ & $1.4 \pm 0.5$ & $4.3 \pm 61.3$ & $142.0 \pm 182.8^{* *}$ & $1.7 \pm 2.1$ & $175.9 \pm 415.5^{\star *}$ \\
\hline TLR-2 & $1.9 \pm 0.6$ & $-1.4 \pm 0.2$ & $-1.9 \pm 0.3$ & $1.2 \pm 0.5$ & $-1.0 \pm 0.5$ & $-2.9 \pm 0.1^{* *}$ \\
\hline TLR-3 & $1.5 \pm 0.5$ & $-1.2 \pm 0.1$ & $-1.6 \pm 0.2$ & $1.4 \pm 0.2$ & $-1.9 \pm 0.1$ & $-1.6 \pm 0.2$ \\
\hline TICAM-1 & $-1.3 \pm 0.4$ & $1.6 \pm 1.2$ & $3.0 \pm 0.6^{*}$ & $1.3 \pm 1.2$ & $2.2 \pm 0.8$ & $1.6 \pm 1.0$ \\
\hline MyD88 & $1.1 \pm 0.3$ & $-1.1 \pm 0.1$ & $-1.2 \pm 0.2$ & $1.3 \pm 0.3$ & $1.7 \pm 0.3$ & $1.8 \pm 0.5$ \\
\hline Foxp3 & $2.4 \pm 0.7$ & $1.4 \pm 0.5$ & $3.4 \pm 2.4^{*}$ & $-1.2 \pm 0.3$ & $4.0 \pm 12.4^{*}$ & $1.6 \pm 0.5$ \\
\hline GATA-3 & $1.1 \pm 0.3$ & $-1.5 \pm 0.2$ & $-1.4 \pm 0.2$ & $-1.1 \pm 0.1$ & $1.5 \pm 0.4$ & $-1.5 \pm 0.2$ \\
\hline NF-kb & $1.0 \pm 0.2$ & $-1.1 \pm 0.1$ & $-1.3 \pm 0.2$ & $1.3 \pm 0.2$ & $-1.8 \pm 0.2$ & $1.2 \pm 0.3$ \\
\hline STAT-3 & $1.1 \pm 0.2$ & $-1.4 \pm 0.1$ & $-1.1 \pm 0.2$ & $1.4 \pm 0.6$ & $1.1 \pm 0.5$ & $1.7 \pm 0.3$ \\
\hline STAT-4 & $1.4 \pm 0.1$ & $1.1 \pm 0.1$ & $-1.3 \pm 0.3$ & $1.1 \pm 0.3$ & $-1.3 \pm 0.1$ & $1.1 \pm 0.2$ \\
\hline STAT-6 & $1.3 \pm 0.2$ & $-1.6 \pm 0.1$ & $-1.0 \pm 0.1$ & $1.3 \pm 0.3$ & $1.1 \pm 0.1$ & $-1.0 \pm 0.2$ \\
\hline T-bet & $3.6 \pm 0.6^{*}$ & $-2.1 \pm 0.1^{*}$ & $-1.0 \pm 0.3$ & $-1.0 \pm 0.1$ & $2.1 \pm 0.6$ & $-2.1 \pm 0.3$ \\
\hline S100A1 & $2.1 \pm 0.3^{*}$ & $-1.2 \pm 0.2$ & $3.5 \pm 1.4^{* *}$ & $3.7 \pm 0.8^{* *}$ & $1.9 \pm 0.3$ & $4.2 \pm 0.6^{* *}$ \\
\hline
\end{tabular}

